Article

\title{
Rapid Evaluation and Optimization of Medium Components Governing Tryptophan Production by Pediococcus acidilactici TP-6 Isolated from Malaysian Food via Statistical Approaches
}

\author{
Ye Heng Lim ${ }^{1}$, Hooi Ling Foo ${ }^{1,2, *} \mathbb{C}$, Teck Chwen Loh ${ }^{3,4, *} \mathbb{C}$, Rosfarizan Mohamad ${ }^{1,2,5}(\mathbb{D}$ and \\ Raha Abdul Rahim 1,6,7 \\ 1 Institute of Bioscience, Universiti Putra Malaysia, UPM Serdang 43400, Selangor, Malaysia; \\ yhlim_0418@hotmail.com (Y.H.L.); farizan@upm.edu.my (R.M.); raha@utem.edu.my (R.A.R.) \\ 2 Department of Bioprocess Technology, Faculty of Biotechnology and Biomolecular Sciences, Universiti Putra \\ Malaysia, UPM Serdang 43400, Selangor, Malaysia \\ 3 Department of Animal Science, Faculty of Agriculture, Universiti Putra Malaysia, UPM Serdang 43400, \\ Selangor, Malaysia \\ 4 Institute of Tropical Agriculture and Food Security, Universiti Putra Malaysia, UPM Serdang 43400, \\ Selangor, Malaysia \\ 5 Institute of Tropical Forestry and Forest Products, Universiti Putra Malaysia, UPM Serdang 43400, \\ Selangor, Malaysia \\ 6 Department of Cell and Molecular Biology, Faculty of Biotechnology and Biomolecular Sciences, Universiti \\ Putra Malaysia, UPM Serdang 43400, Selangor, Malaysia \\ 7 Office of Vice Chancellor, Universiti Teknikal Malaysia Melaka, Jalan Hang Tuah Jaya, Durian Tunggal 76100, \\ Melaka, Malaysia \\ * Correspondence: hlfoo@upm.edu.my (H.L.F.); tcloh@upm.edu.my (T.C.L.); \\ Tel.: +60-3-9769-7476 (H.L.F.); +60-3-97694814 (T.C.L.)
}

Academic Editors: Francesco Vinale and Maria Luisa Balestrieri Received: 10 November 2019; Accepted: 9 December 2019; Published: 11 February 2020

\begin{abstract}
Tryptophan is one of the most extensively used amino acids in livestock industry owing to its effectiveness in enhancing the growth performance of animals. Conventionally, the production of tryptophan relies heavily on genetically modified Escherichia coli but its pathogenicity is a great concern. Our recent study demonstrated that a lactic acid bacterium (LAB), Pediococcus acidilactici TP-6 that isolated from Malaysian food was a promising tryptophan producer. However, the tryptophan production must enhance further for viable industrial application. Hence, the current study evaluated the effects of medium components and optimized the medium composition for tryptophan production by P. acidilactici TP-6 statistically using Plackett-Burman Design, and Central Composite Design. The optimized medium containing molasses $(14.06 \mathrm{~g} / \mathrm{L})$, meat extract $(23.68 \mathrm{~g} / \mathrm{L})$, urea $(5.56 \mathrm{~g} / \mathrm{L})$ and $\mathrm{FeSO}_{4}(0.024 \mathrm{~g} / \mathrm{L})$ significantly enhanced the tryptophan production by $150 \%$ as compared to the control de Man, Rogosa and Sharpe medium. The findings obtained in this study revealed that rapid evaluation and effective optimization of medium composition governing tryptophan production by P. acidilactici TP-6 were feasible via statistical approaches. Additionally, the current findings reveal the potential of utilizing $\mathrm{LAB}$ as a safer alternative tryptophan producer and provides insight for future exploitation of various amino acid productions by LAB.
\end{abstract}

Keywords: Tryptophan production; lactic acid bacteria; Pediococcus acidilactici TP-6; Plackett-Burman design; central composite design 


\section{Introduction}

Fermentation medium plays an indispensable role in the industrial fermentation process due to its impact on the formation of the desired products [1]. A cost-effective medium formulation is crucial in ensuring the economic feasibility of the fermentation process. Hence, optimization of the medium composition is important in order to minimize the cost of production without compromising the production. Conventional method and statistical method are the most common methodologies employed in the optimization study. The conventional method of process optimization is also known as one-factor-at-a-time method by varying one factor while keeping the other factors unchanged until an apparent optimum condition is achieved. However, the conventional optimization method often require large number of experiments and it could be time consuming and laborious. Furthermore, this method is not suitable for multifactor optimization because it is unable to elucidate the interactions between the factors and thus incapable to detect the true optimum condition [2].

The limitation of conventional optimization method can be overcome by using statistical optimization method, which involves a collection of numerous experimental strategies, mathematical procedures and statistical inferences. Unlike conventional optimization method, the statistical optimization method is able to explain the interactions between multiple variables and determine the true optimum based on statistical approaches [3]. One of the most commonly used statistical optimization approach is response surface methodology (RSM). The first-and second-degree models are among the most frequently used approximating polynomial models in RSM. Some of the popular first-order designs that are regularly employed for optimization of the fermentation process include the Plackett-Burman Design (PBD) [4] and the Factorial Design [5]. Meanwhile, the commonly used second-order designs include Central Composite Design (CCD) [6] and Box-Behnken Design [7].

Previous optimization studies on the production of tryptophan have revolved around the conventional producer strains such as E. coli and Corynebacterium glutamicum. For instances, Faghfuri et al. [8] reported that sugar beet molasses was a good source of pyridoxal phosphate (PLP) and serine for tryptophan production by E. coli. Meanwhile, Cheng et al. [9] suggested that the growth and tryptophan production of $E$. coli was inhibited by acetic acid above $2 \mathrm{~g} / \mathrm{L}$ and glucose concentration should be controlled at low level for tryptophan production. Moreover, Hagino and Nakayama [10] reported that molasses, casein enzymatic hydrolysate and $\left(\mathrm{NH}_{4}\right)_{2} \mathrm{SO}_{4}$ were the best carbon, organic nitrogen and inorganic nitrogen source for tryptophan production by C. glutamicum. However, the use of genetically engineered and pathogenic microorganism is a major concern and has urged an exploration for a safer producer. Lactic acid bacteria (LAB) have been revealed to possess the ability to produce various amino acid in several recent studies [11,12]. Apart from its versatility in amino acid production, LAB postbiotic metabolites have been extensively reported to confer various health benefits to animals and enhance their growth performance by regulating the gastrointestinal health and immune response of the animals [13-16].

Tryptophan has gained tremendous attention in recent years, particularly in medical, feed and livestock industries. Tryptophan is known as the fourth limiting amino acid in livestock feed, right after lysine, methionine and threonine amino acids [17]. It has been demonstrated to affect both growth and neurotransmitter metabolism of poultry [18]. It also affects glucose metabolism by inhibiting gluconeogenesis [19]. Moreover, L-tryptophan was found to play a crucial role in improving the growth performance, meat quality, reducing stress, regulating insulin response and protein synthesis in muscles of pigs [20], as well as improving the feed conversion and carcass yield of broilers [21]. In medical field, tryptophan is often used as sedative and antidepressant and hence it is frequently prescribed for the treatment of schizophrenia and alcoholism [22]. Tryptophan also acts as a precursor for serotonin biosynthesis, a neurotransmitter that is responsible to relieve anxiety [23].

The effects of growth medium components on amino acid productions by LAB have not been elucidated previously, despite the effects of the M-17 medium [24] and de Man, Rogosa and Sharpe (MRS) medium [11,25] being reported, for the production of amino acid by LAB. Pediococcus acidilactici TP-6 was previously identified as a superior producer of tryptophan in MRS medium [25]. Nevertheless, 
limited knowledge regarding the nutritional requirements of P. acidilactici TP-6 for its growth and tryptophan production was available. Thus, the objectives of this study were to evaluate the effects of medium components on the growth and tryptophan production of P. acidilactici TP-6 by using PBD, followed by optimization of the medium components for tryptophan production by using steepest ascent method and CCD approaches.

\section{Results and Discussion}

\subsection{Plackett-Burman Design}

The nutritional requirement of $P$. acidilactici TP-6 for tryptophan production was studied by using PBD, where each variable was represented at two levels. A dummy variable $(X)$ that serves as an indicator for the presence of significant interactions between the variables was incorporated in the PBD. The presence of significant interactions between the variables was indicated by high effect values of the dummy variable [26]. Table 1 shows the tryptophan production and cell population of respective trial of PBD. In general, tryptophan production was not detected in most of the experimental runs, suggesting the stringent nutrient requirement of the producer strain for tryptophan production. Run 15 recorded the highest amount of tryptophan production of $22.9 \mathrm{mg} / \mathrm{L}$ of tryptophan, followed by run 18 with $21.27 \mathrm{mg} / \mathrm{L}$ of tryptophan. However, there was no significant difference $(p>0.05)$ between the net tryptophan produced achieved in run 15 and run 18 respectively. Nevertheless, the production of tryptophan by P. acidilactici TP-6 in the control MRS medium $(29.41 \mathrm{mg} / \mathrm{L})$ was still significantly higher $(p<0.05)$ than those achieved in the PBD. Thus, further optimization of the medium composition is mandatory to increase tryptophan yield by P. acidilactici TP-6.

Table 1. Plackett-Burman Design (PBD) matrixes for 22 variables with coded values and their corresponding tryptophan production and cell population of P. acidilactici TP-6.

\begin{tabular}{|c|c|c|c|c|c|c|c|c|c|c|c|c|c|c|c|c|c|c|c|c|c|c|c|c|c|}
\hline $\begin{array}{l}\text { Std } \\
\text { Run }\end{array}$ & A & B & C & D & E & F & G & $\mathbf{H}$ & $\mathbf{J}$ & $\mathbf{K}$ & L & $\mathbf{M}$ & $\mathbf{N}$ & $\mathrm{O}$ & $\mathbf{P}$ & $Q$ & $\mathbf{R}$ & $S$ & $\mathbf{T}$ & U & V & $\mathbf{W}$ & $X$ & $\begin{array}{l}\text { Tryptophan } \\
\text { Production } \\
(\mathrm{mg} / \mathrm{L})\end{array}$ & $\begin{array}{c}\text { Cell } \\
\text { Population } \\
(\log C F U / m L)\end{array}$ \\
\hline 1 & 1 & 1 & 1 & 1 & 1 & -1 & 1 & -1 & 1 & 1 & -1 & -1 & 1 & 1 & -1 & -1 & 1 & -1 & 1 & -1 & -1 & -1 & -1 & $0.00 \pm 0.00^{\mathrm{H}}$ & $8.47 \pm 0.04^{\mathrm{I}}$ \\
\hline 2 & -1 & 1 & 1 & 1 & 1 & 1 & -1 & 1 & -1 & 1 & 1 & -1 & -1 & 1 & 1 & -1 & -1 & 1 & -1 & 1 & -1 & -1 & -1 & $0.00 \pm 0.00^{\mathrm{H}}$ & $9.26 \pm 0.01^{B}$ \\
\hline 3 & -1 & -1 & 1 & 1 & 1 & 1 & 1 & -1 & 1 & -1 & 1 & 1 & -1 & -1 & 1 & 1 & -1 & -1 & 1 & -1 & 1 & -1 & -1 & $0.42 \pm 0.05^{\mathrm{G}}$ & $8.82 \pm 0.03^{F}$ \\
\hline 4 & -1 & -1 & -1 & 1 & 1 & 1 & 1 & 1 & -1 & 1 & -1 & 1 & 1 & -1 & -1 & 1 & 1 & -1 & -1 & 1 & -1 & 1 & -1 & $0.34 \pm 0.02 \mathrm{G}$ & $8.77 \pm 0.04^{F}$ \\
\hline 5 & -1 & -1 & -1 & -1 & 1 & 1 & 1 & 1 & 1 & -1 & 1 & -1 & 1 & 1 & -1 & -1 & 1 & 1 & -1 & -1 & 1 & -1 & 1 & $9.35 \pm 0.05^{\mathrm{D}}$ & $9.10 \pm 0.02^{D}$ \\
\hline 6 & 1 & -1 & -1 & -1 & -1 & 1 & 1 & 1 & 1 & 1 & -1 & 1 & -1 & 1 & 1 & -1 & -1 & 1 & 1 & -1 & -1 & 1 & -1 & $0.00 \pm 0.00^{\mathrm{H}}$ & $9.04 \pm 0.01^{\mathrm{E}}$ \\
\hline 7 & -1 & 1 & -1 & -1 & -1 & -1 & 1 & 1 & 1 & 1 & 1 & -1 & 1 & -1 & 1 & 1 & -1 & -1 & 1 & 1 & -1 & -1 & 1 & $6.81 \pm 0.07^{\mathrm{E}}$ & $8.70 \pm 0.01^{G}$ \\
\hline 8 & 1 & -1 & 1 & -1 & -1 & -1 & -1 & 1 & 1 & 1 & 1 & 1 & -1 & 1 & -1 & 1 & 1 & -1 & -1 & 1 & 1 & -1 & -1 & $16.69 \pm$ & $8.75 \pm 0$ \\
\hline 9 & -1 & 1 & -1 & 1 & -1 & -1 & -1 & -1 & 1 & 1 & 1 & 1 & 1 & -1 & 1 & -1 & 1 & 1 & -1 & -1 & 1 & 1 & -1 & $0.00 \pm 0.00^{\mathrm{H}}$ & $7.33 \pm 0.01 \mathrm{M}$ \\
\hline 10 & -1 & -1 & 1 & -1 & 1 & -1 & -1 & -1 & -1 & 1 & 1 & 1 & 1 & 1 & -1 & 1 & -1 & 1 & 1 & -1 & -1 & 1 & 1 & $0.00 \pm 0.00^{\mathrm{H}}$ & $7.89 \pm 0.02 \mathrm{~L}$ \\
\hline 11 & 1 & -1 & -1 & 1 & -1 & 1 & -1 & -1 & -1 & -1 & 1 & 1 & 1 & 1 & 1 & -1 & 1 & -1 & 1 & 1 & -1 & -1 & 1 & $0.00 \pm 0.00^{\mathrm{H}}$ & $9.22 \pm$ \\
\hline 12 & 1 & 1 & -1 & -1 & 1 & -1 & 1 & -1 & -1 & -1 & -1 & 1 & 1 & 1 & 1 & 1 & -1 & 1 & -1 & 1 & 1 & -1 & -1 & $0.00 \pm 0.00^{\mathrm{H}}$ & $8.79 \pm 0.02^{F}$ \\
\hline 13 & -1 & 1 & 1 & -1 & -1 & 1 & -1 & 1 & -1 & -1 & -1 & -1 & 1 & 1 & 1 & 1 & 1 & -1 & 1 & -1 & 1 & 1 & -1 & $0.00 \pm 0.00^{\mathrm{H}}$ & $9.02 \pm 0.03^{\mathrm{E}}$ \\
\hline 14 & -1 & -1 & 1 & 1 & -1 & -1 & 1 & -1 & 1 & -1 & -1 & -1 & -1 & 1 & 1 & 1 & 1 & 1 & -1 & 1 & -1 & 1 & 1 & $4.85 \pm$ & $0.00^{\mathrm{H}}$ \\
\hline 15 & 1 & -1 & -1 & 1 & 1 & -1 & -1 & 1 & -1 & 1 & -1 & -1 & -1 & -1 & 1 & 1 & 1 & 1 & 1 & -1 & 1 & -1 & 1 & $22.94 \pm 0.79^{\text {B }}$ & $9.19 \pm 0.01^{C}$ \\
\hline 16 & 1 & 1 & -1 & -1 & 1 & 1 & -1 & -1 & 1 & -1 & 1 & -1 & -1 & -1 & -1 & 1 & 1 & 1 & 1 & 1 & -1 & 1 & -1 & $0.00 \pm 0.00^{\mathrm{H}}$ & $8.75 \pm 0.03^{\mathrm{FG}}$ \\
\hline 17 & -1 & 1 & 1 & -1 & -1 & 1 & 1 & -1 & -1 & 1 & -1 & 1 & -1 & -1 & -1 & -1 & 1 & 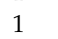 & 1 & 1 & 1 & -1 & 1 & 0.00 & $8.75 \pm 0.02 \mathrm{FG}$ \\
\hline 18 & 1 & -1 & 1 & 1 & -1 & -1 & 1 & 1 & -1 & -1 & 1 & -1 & 1 & -1 & -1 & -1 & -1 & 1 & 1 & 1 & 1 & 1 & -1 & $21.27 \pm 0.24^{B}$ & $7.88 \pm 0.02 \mathrm{~L}$ \\
\hline 19 & -1 & 1 & -1 & 1 & 1 & -1 & -1 & 1 & 1 & -1 & -1 & 1 & -1 & 1 & -1 & -1 & -1 & -1 & 1 & 1 & 1 & 1 & 1 & $10.58 \pm 0.25^{\mathrm{D}}$ & $8.47 \pm 0.01^{\mathrm{K}}$ \\
\hline 20 & 1 & -1 & 1 & -1 & 1 & 1 & -1 & -1 & 1 & 1 & -1 & -1 & 1 & -1 & 1 & -1 & -1 & -1 & -1 & 1 & 1 & 1 & 1 & $0.00 \pm 0.00^{\mathrm{H}}$ & $8.50 \pm 0.01 \mathrm{IJ}$ \\
\hline 21 & 1 & 1 & -1 & 1 & -1 & 1 & 1 & -1 & -1 & 1 & 1 & -1 & -1 & 1 & -1 & 1 & -1 & -1 & -1 & -1 & 1 & 1 & 1 & $0.00 \pm 0.00^{\mathrm{H}}$ & $9.11 \pm 0.01^{\mathrm{D}}$ \\
\hline 22 & 1 & 1 & 1 & -1 & 1 & -1 & 1 & 1 & -1 & -1 & 1 & 1 & -1 & -1 & 1 & -1 & 1 & -1 & -1 & -1 & -1 & 1 & 1 & $0.00 \pm 0.00^{\mathrm{H}}$ & $9.34 \pm 0.02 \mathrm{AB}$ \\
\hline 23 & 1 & 1 & 1 & 1 & -1 & 1 & -1 & 1 & 1 & -1 & -1 & 1 & 1 & -1 & -1 & 1 & -1 & 1 & -1 & -1 & -1 & -1 & 1 & $0.35 \pm 0.01^{\mathrm{G}}$ & $9.05 \pm 0.01^{\mathrm{E}}$ \\
\hline 24 & -1 & -1 & -1 & -1 & -1 & -1 & -1 & -1 & -1 & -1 & -1 & -1 & -1 & -1 & -1 & -1 & -1 & -1 & -1 & -1 & -1 & -1 & -1 & $0.00 \pm 0.00^{\mathrm{H}}$ & $7.33 \pm 0.02^{\mathrm{M}}$ \\
\hline MRS & 1 & -1 & -1 & -1 & -1 & 1 & 1 & 1 & 1 & -1 & -1 & -1 & -1 & 1 & 1 & 1 & 1 & 1 & -1 & -1 & -1 & -1 & -1 & $29.41 \pm 0.76^{\mathrm{A}}$ & $9.41 \pm 0.01^{\mathrm{A}}$ \\
\hline
\end{tabular}

Note: Values are mean \pm SEM, $n=3$. Mean \pm SEM within the same column that share a common superscript (A-M) are not significantly different $(p>0.05)$.

Table 2 presents the ANOVA of the PBD for the effects of medium components on tryptophan production by $P$. acidilactici TP-6. The low $\mathrm{p}$-value of the model (0.0019) revealed that the model was highly significant $(p<0.01)$ and it is highly unlikely ( $>99 \%$ confidence) that the large F-value of the 
model was attributed to noise. Moreover, the model was able to elucidate $99 \%$ of variation in response, owing to its high coefficient of determination $\left(R^{2}=0.9986\right)$. Additionally, the "predicted $R^{2 \text { " }}(0.9490)$ and the "adjusted $R^{2 "}(0.9919)$ values were close to 1 and in reasonable agreement, implying the great correlation between experimental and predicted values and hence the suggested PBD model was a good model [27]. Furthermore, the model is suitable for navigating the design space owing to its adequate signal to noise ratio, which was reflected by the high adequate precision value of 110.181 (much greater than 4 ).

Based on the ANOVA of tryptophan production (Table 2), majority of the studied variables contributed significantly $(p<0.05)$ to tryptophan production by P. acidilactici TP- 6 , whereby up to 17 variables showed a p-value less than 0.05 except fructose, Tween 80 and biotin, which were not significant $(p>0.05)$. Among the 17 significant variables, 16 of them were highly significant $(p<0.01)$ except glucose and $\mathrm{MgSO}_{4}$, which were significant $(p<0.05)$. Additionally, the dummy variable was revealed to be highly significant $(p<0.01)$. The unexpectedly high significant effect of the dummy variable implied the presence of significant interactions between the variables [26]. Hence, a design with higher resolution is required to elucidate the interaction [28]. The net tryptophan production $(\mathrm{Y})$ by $P$. acidilactici TP-6 can be expressed in terms of coded symbols (A-X) as shown in the following regression Equation (1):

$$
\begin{gathered}
\mathrm{Y}=1.21-0.51 \mathrm{~A}-4.25 \mathrm{~B}-0.16 \mathrm{C}+2.23 \mathrm{D}-2.03 \mathrm{E}-2.56 \mathrm{~F}-1.71 \mathrm{G}+4.97 \mathrm{H}+1.41 \mathrm{~J}+1.98 \mathrm{~L}- \\
1.95 \mathrm{M}-1.51 \mathrm{~N}-1.79 \mathrm{O}-2.34 \mathrm{P}+0.56 \mathrm{Q}+2.01 \mathrm{R}+0.29 \mathrm{~S}+2.81 \mathrm{~T}+1.97 \mathrm{~V}+0.30 \mathrm{~W}+1.64 \mathrm{X}
\end{gathered}
$$

Table 2. ANOVA of PBD for the effects of medium components on tryptophan production by

\begin{tabular}{|c|c|c|c|c|c|c|}
\hline Source & $\begin{array}{l}\text { Sum of } \\
\text { Squares }\end{array}$ & df & $\begin{array}{l}\text { Mean } \\
\text { Square }\end{array}$ & F Value & $\begin{array}{l}p \text {-Value } \\
\text { Prob }>\text { F }\end{array}$ & \\
\hline Model & 2428.91 & 21 & 115.66 & 520.43 & $<0.01$ & significant \\
\hline A-Glucose & 6.13 & 1 & 6.13 & 27.56 & 0.03 & significant \\
\hline B-Sucrose & 433.36 & 1 & 433.36 & 1949.90 & $<0.01$ & significant \\
\hline C-Fructose & 0.61 & 1 & 0.61 & 2.76 & 0.24 & \\
\hline D-Lactose & 119.36 & 1 & 119.36 & 537.05 & $<0.01$ & significant \\
\hline E-Molasses & 98.68 & 1 & 98.68 & 444.03 & $<0.01$ & significant \\
\hline F-Yeast extract & 156.85 & 1 & 156.85 & 705.75 & $<0.01$ & significant \\
\hline G-Peptone & 70.03 & 1 & 70.03 & 315.12 & $<0.01$ & significant \\
\hline H-Meat extract & 592.62 & 1 & 592.62 & 2666.50 & $<0.01$ & significant \\
\hline $\mathrm{J}-\mathrm{K}_{2} \mathrm{HPO}_{4}$ & 47.76 & 1 & 47.76 & 214.88 & $<0.01$ & significant \\
\hline L-Urea & 93.75 & 1 & 93.75 & 421.83 & $<0.01$ & significant \\
\hline $\mathrm{M}-\mathrm{NH}_{4} \mathrm{NO}_{3}$ & 90.83 & 1 & 90.83 & 408.69 & $<0.01$ & significant \\
\hline $\mathrm{N}-\left(\mathrm{NH}_{4}\right)_{2} \mathrm{SO}_{4}$ & 54.88 & 1 & 54.88 & 246.92 & $<0.01$ & significant \\
\hline $\mathrm{O}-\left(\mathrm{NH}_{4}\right)_{2} \mathrm{HC}_{6} \mathrm{H}_{5} \mathrm{O}_{7}$ & 77.00 & 1 & 77.00 & 346.49 & $<0.01$ & significant \\
\hline $\mathrm{P}-\mathrm{NaOAc}$ & 131.64 & 1 & 131.64 & 592.30 & $<0.01$ & significant \\
\hline Q-MgSO 4 & 7.54 & 1 & 7.54 & 33.93 & 0.03 & significant \\
\hline $\mathrm{R}-\mathrm{MnSO}_{4}$ & 97.21 & 1 & 97.21 & 437.39 & $<0.01$ & significant \\
\hline S-Tween 80 & 2.04 & 1 & 2.04 & 9.19 & 0.09 & \\
\hline $\mathrm{T}-\mathrm{FeSO}_{4}$ & 188.94 & 1 & 188.94 & 850.15 & $<0.01$ & significant \\
\hline $\mathrm{V}-\mathrm{CuSO} \mathrm{S}_{4}$ & 92.90 & 1 & 92.90 & 418.02 & $<0.01$ & significant \\
\hline W-Biotin & 2.09 & 1 & 2.09 & 9.42 & 0.09 & \\
\hline X-dummy & 64.69 & 1 & 64.69 & 291.09 & $<0.01$ & significant \\
\hline Residual & 0.44 & 2 & 0.22 & & & \\
\hline Cor Total & 2429.36 & 23 & & & & \\
\hline
\end{tabular}
P. acidilactici TP-6.

Note: $R^{2}$ : 0.9998; Adj $R^{2}$ : 0.9979; Pred $R^{2}$ : 0.9737; Adeq Precision: 110.181. 
Figure 1 illustrates the impact of each medium component on tryptophan production by P. acidilactici TP-6. Among the 22 studied variables, 10 of them, including meat extract, $\mathrm{FeSO}_{4}$, lactose, $\mathrm{MnSO}_{4}$, urea, $\mathrm{CuSO}_{4}, \mathrm{~K}_{2} \mathrm{HPO}_{4}, \mathrm{MgSO}_{4}$, biotin and Tween 80, exerted a stimulatory effect on tryptophan production, whereas the remaining 12 variables demonstrated an inhibitory effect. Out of the 10 variables that exhibited positive effect, 7 of them including meat extract, $\mathrm{FeSO}_{4}, \mathrm{lactose}_{\text {, }}$ $\mathrm{MnSO}_{4}$, urea, $\mathrm{CuSO}_{4}$ and $\mathrm{K}_{2} \mathrm{HPO}_{4}$ were highly significant at p-value less than 0.01 , whereas $\mathrm{MgSO}_{4}$ was significant $(p<0.05)$ as shown in Table 2. In contrast, biotin and Tween 80 did not contribute significantly $(p>0.05)$ to the tryptophan production by P. acidilactici TP-6. On the other hand, 8 out of the 12 variables that exhibited a negative effect were highly significant $(p<0.01)$ and one of them was significant $(p<0.05)$. Meanwhile, the other 3 variables did not affect tryptophan production significantly $(p>0.05)$.

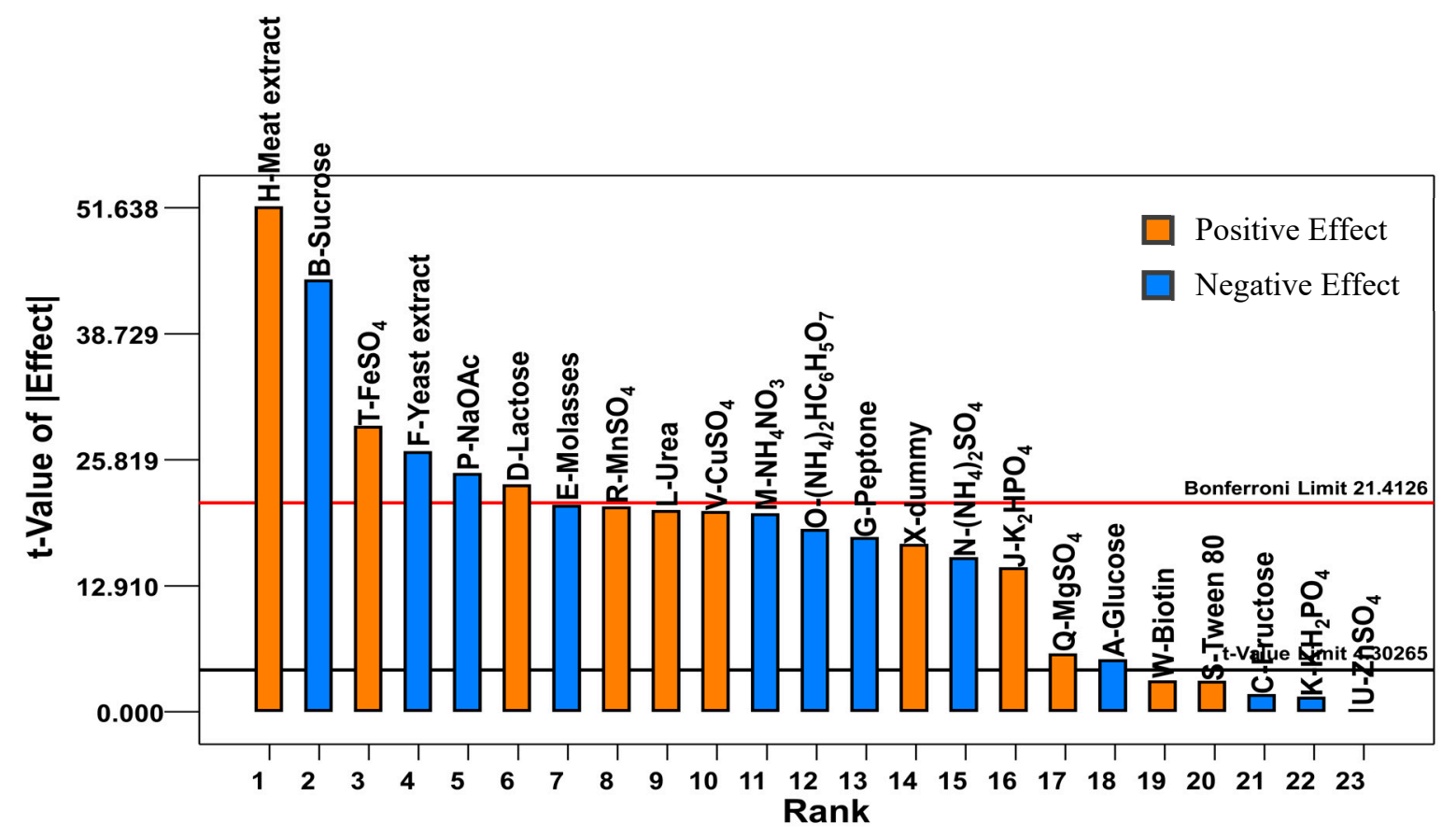

Figure 1. Effects of different medium components on tryptophan production by P. acidilactici TP-6.

Carbon sources play an essential role in the biosynthesis of tryptophan where the metabolism of carbon sources provides erythrose-4-phosphate and phosphoenolpyruvate, which act as precursors for tryptophan biosynthesis [29]. Among the five studied carbon sources, only lactose demonstrated a highly significant $(p<0.01)$ stimulatory effect on tryptophan production by P. acidilactici TP-6. Production of tryptophan by Lactobacilli strains in medium containing lactose as sole carbon source was also reported by Tarek and Hesham [24]. Meanwhile, the other 4 carbon sources (sucrose, molasses, glucose and fructose) exhibited a negative effect on tryptophan production by P. acidilactici TP-6 with sucrose, molasses and glucose being significant $(p<0.05)$ and fructose was insignificant $(p>0.05)$. This is in contrast with the findings of several other studies conducted by other researchers, where the tested carbon sources often possessed a stimulatory effect on the production of amino acid. For instance, molasses was used for the production of tryptophan by C. glutamicum [8]. Furthermore, molasses was reported as the most suitable carbon source for the synthesis of tryptophan by C. glutamicum [10]. The use of glucose for the production of various amino acid by C. glutamicum [30-32] and E. coli [33,34] was also well documented. Furthermore, sucrose was identified as the best carbon source for threonine production by Escherichia coli TRFC [35] and it was used as the sole carbon source for threonine production by a recombinant E. coli in a separate study conducted by Wang et al. [36]. Nevertheless, fructose was revealed as one of the best carbon sources for glutamate production by Arthrobacter 
globiformis [37]. The discrepancy of the effects of different carbon sources on amino acid production might be attributed to the use of different microorganisms as producer strains.

Among the three tested organic nitrogen sources, only meat extract demonstrated a highly significant stimulatory effect $(p<0.01)$, whereas yeast extract and peptone showed a highly significant inhibitory effect $(p<0.01)$. The organic nitrogen source is crucial for the biosynthesis of tryptophan, where it is responsible for supplying serine for the formation of tryptophan from (3-Indoyl)-glycerolphosphate catalyzed by the enzyme tryptophan synthase [38]. The high stimulatory effect of meat extract on tryptophan production by P. acidilactici TP-6 might be due to the rich serine content of meat extract [39]. Additionally, the positive effect of meat extract on tryptophan production could be attributed to its rich vitamin content, which acted as coenzymes for the activation of enzymes involved in the biosynthesis of tryptophan. For instance, meat extract contains an abundant amount of riboflavin [40], which can be converted into flavin mononucleotide, an essential coenzyme for chorismate synthase enzyme that is responsible for the synthesis of chorismate from 5-o-(1-carboxyvinyl)-3-phosphate [41]. Moreover, vitamin $B_{3}$, which is abundant in meat extract, will be metabolized into NADPH that functions as coenzyme for the action of shikimate dehydrogenase enzyme, which is accountable for the transformation of 3-dehydroshikimate into shikimate. Lim et al. [25] had demonstrated the effect of medium containing meat extract, yeast extract and peptone for the production of amino acid by LAB. In comparison, yeast extract was used for the production of tryptophan by E. coli in a study conducted by Faghfuri et al. [8]. In addition, Hagino and Nakayama [10] demonstrated that yeast extract was the best organic nitrogen source for tryptophan synthesis by C. glutamicum. Nevertheless, the present study revealed that yeast extract demonstrated an inhibitory effect on tryptophan production by P. acidilactici TP-6. Differences in the preference of organic nitrogen sources might be attributed to the use of different microorganism as the amino acid producer strain in the study.

On the other hand, all the inorganic nitrogen sources used in the current study contributed significantly $(p<0.05)$ to tryptophan production by P. acidilactici TP-6 (Table 2). However, most of them demonstrated a negative effect, except urea which exhibited a stimulatory effect. The significant positive impact of urea on the production of tryptophan might be attributed to its function to supply ammonia for the formation of anthranilate from chorismate catalyzed by the enzyme anthranilate synthase during tryptophan biosynthesis [42]. Urea was used as an inorganic nitrogen source for glutamate production by C. glutamicum [43] and Brevibacterium sp. [44], respectively, whereas $\mathrm{NH}_{4} \mathrm{NO}_{3}$ was utilized as the sole inorganic nitrogen source for glutamate production by LAB in a study conducted by Zareian et al. [45]. On the other hand, the use of $\left(\mathrm{NH}_{4}\right)_{2} \mathrm{SO}_{4}$ as inorganic nitrogen source for the production of various amino acid by C. glutamicum $[31,32]$ and E. coli $[8,33-36]$ were well documented.

In the meantime, 5 out of 8 mineral sources including $\mathrm{FeSO}_{4}, \mathrm{MnSO}_{4}, \mathrm{CuSO}_{4}, \mathrm{~K}_{2} \mathrm{HPO}_{4}$ and $\mathrm{MgSO}_{4}$ exhibited positive effect on tryptophan production by P. acidilactici TP-6 significantly $(p<0.05)$, whereas $\mathrm{NaOAc}$ contributed significantly $(p<0.05)$ on tryptophan production in a negative manner. Furthermore, $\mathrm{KH}_{2} \mathrm{PO}_{4}$ and $\mathrm{ZnSO}_{4}$ displayed an inhibitory effect on tryptophan production by the producer strain but the effect was insignificant $(p>0.05)$. The significant effects of minerals such as $\mathrm{FeSO}_{4}, \mathrm{MnSO}_{4}, \mathrm{CuSO}_{4}, \mathrm{~K}_{2} \mathrm{HPO}_{4}$ and $\mathrm{MgSO}_{4}$ for the production of various amino acid have been demonstrated for E. coli $[35,36]$ and C. glutamicum $[32,46]$, indicating the importance of minerals for amino acid production. Many metal ions play an essential role as cofactor that is required for catalytic activity of enzymes to ensure proper functioning of biological system [47].

Findings obtained in the current study revealed that most of the divalent cations displayed a stimulatory effect on tryptophan production except $\mathrm{Zn}^{2+}$. The crucial role of divalent cations such as $\mathrm{Fe}^{2+}, \mathrm{Mn}^{2+}, \mathrm{Co}^{2+}$ and $\mathrm{Mg}^{2+}$ on enzymes involved in biosynthesis of tryptophan has been well documented, where they often possessed a stimulatory effect. For instances, Zalkin and Kling [48] reported that the enzyme anthranilate synthase has an absolute requirement for $\mathrm{Mg}^{2+}$, while Hertel et al. [49] discovered that $\mathrm{Fe}^{2+}$ and $\mathrm{Co}^{2+}$ could be used to substitute $\mathrm{Mg}^{2+}$ as a cofactor for anthranilate synthase. Moreover, Widholm [50] also found that $\mathrm{Mn}^{2+}$ or $\mathrm{Co}^{2+}$ could substitute $\mathrm{Mg}^{2+}$ for the enzyme anthranilate synthase. The negative effect of $\mathrm{Zn}^{2+}$ on the production of tryptophan by 
P. acidilactici TP-6 in the present study might be due to its inhibitory effect on the enzyme anthranilate synthase as suggested by Hertel et al. [49] and Widholm [50].

In comparison, the biotin vitamin B employed in the current study demonstrated a stimulatory effect on the production of tryptophan by P. acidilactici TP-6, despite the effect being insignificant $(p>0.05)$. This is in contrast with previous reports, whereby biotin was often essential for the production of amino acid by microorganisms such as E. coli [33] and Corynebacterium [32]. One of the possible explanations for the insignificant impact of biotin on tryptophan production by $P$. acidilactici TP-6 might be attributed to different nutrient requirement between LAB and other microorganisms for amino acid production, implying that the nutrient requirement for amino acid production could be species dependent. Another possible explanation might be due to low requirement of vitamin biotin, where it is often required in minute amount. Hence, inclusion of molasses which contain high biotin content [51] in the medium formulation could provide sufficient biotin to the producer strain of P. acidilactici TP-6 that used in this study.

On the other hand, the non-ionic surfactant of Tween 80 that used in the present study displayed a stimulatory effect on the production of tryptophan but it was not significant $(p>0.05)$. To the best of our knowledge, there were no reports available regarding the role of Tween 80 in the production of amino acid thus far. Despite Tween 80 has been included in the medium formulation for glutamate production by Brevibacterium sp. in a study conducted by Nampoothiri and Pandey [44], its significance level was not elucidated. However, Tween 80 is well-known for its crucial role for the production of various LAB metabolites. For instance, the supplementation of Tween 80 was found to critically boost the bacteriocins production [52]. Tween 80 acts as biosurfactant which is responsible to modify the fluidity and permeability of the cell membrane of producer strain. This in turn facilitates the secretion of metabolites extracellularly [53].

The effects of various medium components on the growth of P. acidilactici TP-6 were elucidated by the 24 experimental trials of PBD. The corresponding cell population of P. acidilactici TP-6 in each experimental run is presented in Table 1 . Among the 24 experimental runs, the highest cell population was detected in run 22 with $9.34 \log \mathrm{CFU} / \mathrm{mL}$ and it was not significantly different $(p>0.05)$ as compared to control $(9.41 \log \mathrm{CFU} / \mathrm{mL})$. In contrast, run 9 and run 24 showed the lowest cell population of merely $7.33 \log C F U / m L$. Absence of organic nitrogen source or carbon source in both runs, which was crucial for the growth of LAB [54] and could be the reason attributing to the low cell growth in both runs.

Table 3 displays the ANOVA of the PBD for the effects of medium components on the cell growth of P. acidilactici TP-6. The low p-value of the model $(<0.01)$ revealed that the model was highly significant $(p<0.01)$ and it is highly unlikely ( $>99 \%$ confidence) that the large F-value of the model this large was attributed to noise. Moreover, the model exhibits great predictive strength and was able to elucidate $99 \%$ of variation in response due to its high $\mathrm{R}^{2}$ value $(0.9986)$. Additionally, the "predicted $\mathrm{R}^{2 \text { " }}(0.9490)$ and the "adjusted $R^{2 \text { " }}(0.9919)$ values were in reasonable agreement (difference $\left.<0.2\right)$, implying the great correlation between experimental and predicted values and the suggested model was significant. Furthermore, the model is suitable for navigating the design space owing to its adequate signal to noise ratio, which was reflected by the high adequate precision value (44.159) that was much greater than 4 .

Among the 22 studied variables, 16 variables were revealed to exhibit a significant effect $(p<0.05)$ on the growth of $P$. acidilactici TP-6. Out of the 16 significant variables, 12 of them including glucose, sucrose, molasses, yeast extract, peptone, meat extract, $\left(\mathrm{NH}_{4}\right)_{2} \mathrm{SO}_{4},\left(\mathrm{NH}_{4}\right)_{2} \mathrm{HC}_{6} \mathrm{H}_{5} \mathrm{O}_{7}, \mathrm{NaOAc}, \mathrm{MgSO}_{4}$, $\mathrm{MnSO}_{4}$ and biotin were highly significant $(p<0.01)$. Furthermore, the $\mathrm{p}$-value of the dummy variable was less than 0.01 , implying the possible presence of interactions between the variables, which have to be elucidated using a higher resolution design in the subsequent experiment [28]. The growth of 
P. acidilactici TP-6 (Z) can be expressed in the term of the coded symbol as shown in the following first-order regression Equation (2):

$$
\begin{gathered}
\mathrm{Z}=8.67+0.17 \mathrm{~A}+0.082 \mathrm{~B}+0.023 \mathrm{C}+0.11 \mathrm{E}+0.28 \mathrm{~F}+0.11 \mathrm{G}+0.21 \mathrm{H}-0.04 \mathrm{~J}-0.025 \mathrm{~K}- \\
0.11 \mathrm{~N}+0.14 \mathrm{O}+0.15 \mathrm{P}+0.11 \mathrm{Q}+0.1 \mathrm{R}-0.037 \mathrm{~S}+0.031 \mathrm{U}-0.029 \mathrm{~V}-0.11 \mathrm{~W}+0.16 \mathrm{X}
\end{gathered}
$$

\begin{tabular}{|c|c|c|c|c|c|c|}
\hline Source & $\begin{array}{l}\text { Sum of } \\
\text { Squares }\end{array}$ & df & $\begin{array}{c}\text { Mean } \\
\text { Square }\end{array}$ & F Value & $\begin{array}{l}p \text {-Value } \\
\text { Prob }>\text { F }\end{array}$ & \\
\hline Model & 7.15 & 19 & 0.38 & 148.54 & $<0.01$ & significant \\
\hline A-Glucose & 0.68 & 1 & 0.68 & 269.27 & $<0.01$ & significant \\
\hline B-Sucrose & 0.16 & 1 & 0.16 & 63.98 & $<0.01$ & significant \\
\hline C-Fructose & 0.01 & 1 & 0.01 & 4.88 & 0.09 & \\
\hline E-Molasses & 0.27 & 1 & 0.27 & 107.47 & $<0.01$ & significant \\
\hline F-Yeast extract & 1.83 & 1 & 1.83 & 721.80 & $<0.01$ & significant \\
\hline G-Peptone & 0.29 & 1 & 0.29 & 112.71 & $<0.01$ & significant \\
\hline H-Meat extract & 1.05 & 1 & 1.05 & 414.04 & $<0.01$ & significant \\
\hline $\mathrm{J}-\mathrm{K}_{2} \mathrm{HPO}_{4}$ & 0.04 & 1 & 0.04 & 15.23 & 0.02 & significant \\
\hline $\mathrm{K}-\mathrm{KH}_{2} \mathrm{PO}_{4}$ & 0.01 & 1 & 0.01 & 5.82 & 0.07 & \\
\hline $\mathrm{N}-\left(\mathrm{NH}_{4}\right)_{2} \mathrm{SO}_{4}$ & 0.30 & 1 & 0.30 & 119.34 & $<0.01$ & significant \\
\hline $\mathrm{O}-\left(\mathrm{NH}_{4}\right)_{2} \mathrm{HC}_{6} \mathrm{H}_{5} \mathrm{O}_{7}$ & 0.46 & 1 & 0.46 & 179.90 & $<0.01$ & significant \\
\hline P-NaOAc & 0.51 & 1 & 0.51 & 200.63 & $<0.01$ & significant \\
\hline Q-MgSO 4 & 0.32 & 1 & 0.32 & 125.26 & $<0.01$ & significant \\
\hline $\mathrm{R}-\mathrm{MnSO}_{4}$ & 0.25 & 1 & 0.25 & 100.07 & $<0.01$ & significant \\
\hline S-Tween 80 & 0.03 & 1 & 0.03 & 13.04 & 0.02 & significant \\
\hline $\mathrm{U}-\mathrm{ZnSO}_{4}$ & 0.02 & 1 & 0.02 & 9.40 & 0.04 & significant \\
\hline $\mathrm{V}-\mathrm{CuSO}_{4}$ & 0.02 & 1 & 0.02 & 8.15 & 0.05 & significant \\
\hline W-Biotin & 0.31 & 1 & 0.31 & 123.62 & $<0.01$ & significant \\
\hline X-dummy & 0.58 & 1 & 0.58 & 227.63 & $<0.01$ & significant \\
\hline Residual & 0.01 & 4 & 0.00 & & & \\
\hline Cor Total & 7.16 & 23 & & & & \\
\hline
\end{tabular}

Table 3. ANOVA of PBD for the effects of medium components on the growth of P. acidilactici TP-6.

Note: $R^{2}$ : 0.9986; Adj $R^{2}$ : 0.9919; Pred $R^{2}$ : 0.9490; Adeq Precision: 44.159.

The effects of medium components on the growth of P. acidilactici TP-6 are depicted in Figure 2. Apart from biotin, $\left(\mathrm{NH}_{4}\right)_{2} \mathrm{SO}_{4}, \mathrm{~K}_{2} \mathrm{HPO}_{4}$, Tween $80, \mathrm{CuSO}_{4}$ and $\mathrm{KH}_{2} \mathrm{PO}_{4}$, which demonstrated an inhibitory effect, the remaining studied variables affected the cell growth of P. acidilactici TP-6 in a positive manner. Among the 16 positive effect variables, 11 of them were significant $(p<0.05)$, except fructose, $\mathrm{NH}_{4} \mathrm{NO}_{3}, \mathrm{FeSO}_{4}$, lactose and urea, which were insignificant $(p>0.05)$. In addition, the present study revealed that all the tested carbon sources exerted a stimulatory effect on the cell growth of $P$. acidilactici TP-6 with glucose giving the highest stimulatory effect, followed by molasses and sucrose (Figure 2). The stimulatory effect of glucose, molasses and sucrose were significant $(p<0.05)$. Contradictorily, the stimulatory effect of fructose and lactose on the cell growth of P. acidilactici TP-6 was not significant $(p>0.05)$. The strong stimulatory effect of various carbon sources on the cell growth of P. acidilactici TP-6 implied that the carbon source was crucial for the survival and growth of producer strain of P. acidilactici TP-6. Furthermore, P. acidilactici TP-6 was able to utilize an array of carbon sources for its growth. This is in agreement with the findings reported by several studies, whereby various $\mathrm{LAB}$ were demonstrated to have the capability to utilize various carbon sources for their growth [55-57].

Similarly, the organic nitrogen sources used in the present study including yeast extract, meat extract and peptone also demonstrated highly significant $(p<0.01)$ stimulatory effect towards the growth of P. acidilactici TP-6 with yeast extract exhibited the highest stimulatory effect. The significant impact of organic nitrogen sources on the cell growth of P. acidilactici TP-6 could be attributed to its 
fastidious nutrient requirements. Typically, LAB are unable to survive on inorganic nitrogen solely. They were able to thrive in medium containing organic nitrogen such as complex proteins and peptides. A similar finding was also reported by Rodrigues et al. [58], where all the studied organic nitrogen sources contributed significantly to the growth of Lactococcus lactis 53 in a positive manner. The organic nitrogen with the highest stimulatory effect was also found to be yeast extract. Ooi et al. [59] also reported that yeast extract was crucial for bacteriocin production by L. plantarum I-UL4, whereby the bacteriocin production was only detected when yeast extract was present. Similar findings were reported by Lim et al. [60], where all the organic nitrogen sources demonstrated a significant stimulatory effect $(p<0.05)$ on the growth of Pediococcus pentosaceus TL-3, highlighting the crucial role of organic nitrogen sources for the growth of P. pentosaceus TL-3.

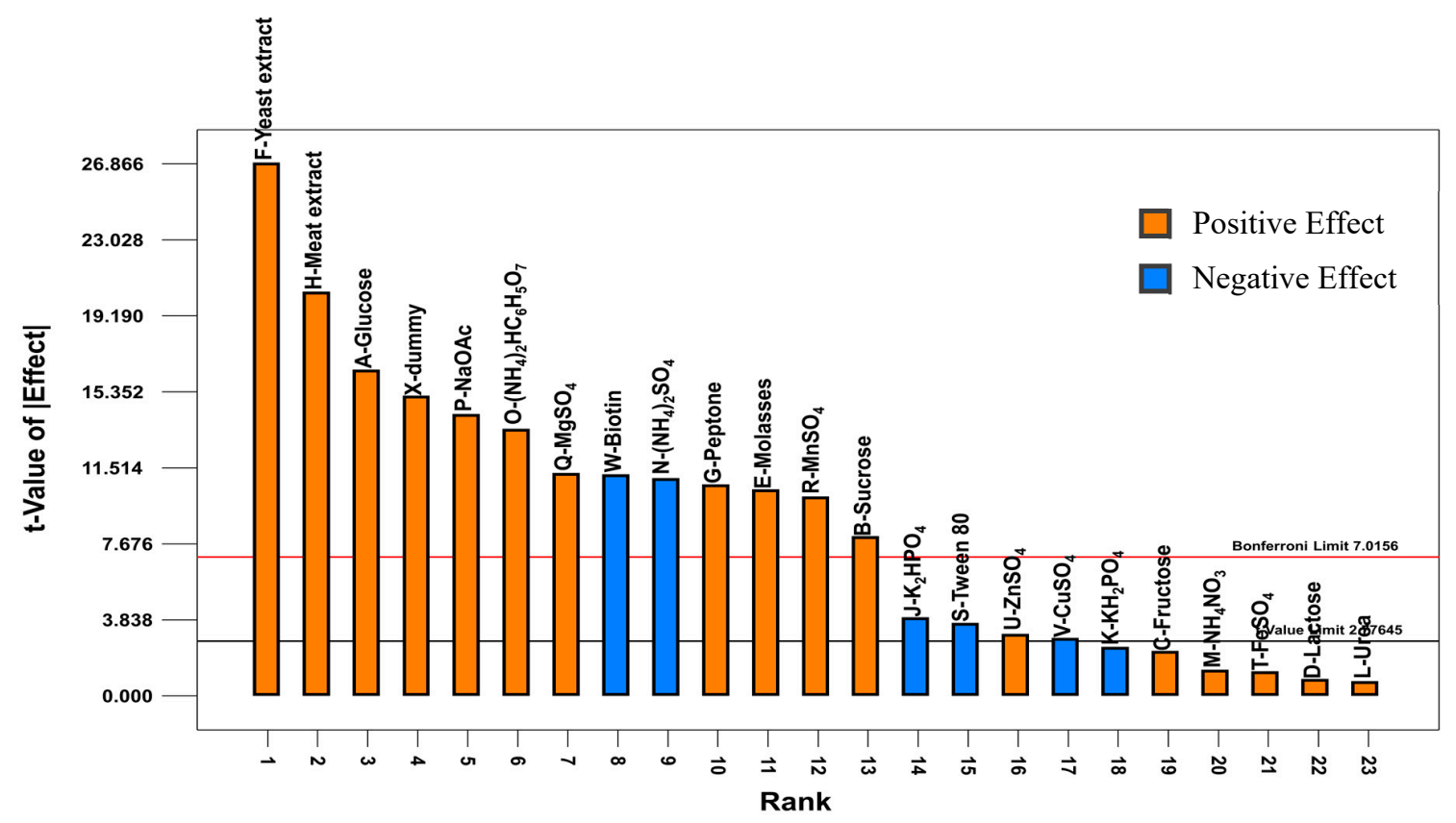

Figure 2. Effects of medium compositions on growth of P. acidilactici TP-6.

Unlike organic nitrogen sources, the effect of inorganic nitrogen sources on the growth of P. acidilactici TP-6 was less prominent, whereby only 2 out of the 4 studied inorganic nitrogen sources affected the cell growth of $P$. acidilactici TP-6 significantly $(p<0.05)$ with $\left(\mathrm{NH}_{4}\right)_{2} \mathrm{HC}_{6} \mathrm{H}_{5} \mathrm{O}_{7}$ demonstrated a highly significant stimulatory effect $(p<0.01)$, whereas $\left(\mathrm{NH}_{4}\right)_{2} \mathrm{SO}_{4}$ exerted a highly significant inhibitory effect $(p<0.01)$. The stimulatory effect of $\left(\mathrm{NH}_{4}\right)_{2} \mathrm{HC}_{6} \mathrm{H}_{5} \mathrm{O}_{7}$ on the growth of LAB was also reported by Hwang et al. [61], where $\left(\mathrm{NH}_{4}\right)_{2} \mathrm{HC}_{6} \mathrm{H}_{5} \mathrm{O}_{7}$ promoted the growth of L. plantarum Pi06. However, Rodrigues et al. [58] reported contradictory finding, where $\left(\mathrm{NH}_{4}\right)_{2} \mathrm{HC}_{6} \mathrm{H}_{5} \mathrm{O}_{7}$ did not exhibit significant effect on the cell growth of studied LAB. This implied that the effect of inorganic nitrogen sources on the cell growth of $\mathrm{LAB}$ could be strain dependent. Nevertheless, although the remaining 2 inorganic nitrogen sources $\left(\mathrm{NH}_{4} \mathrm{NO}_{3}\right.$ and urea) wielded a positive effect but the effect was insignificant $(p>0.05)$. The insignificance of inorganic nitrogen sources on LAB growth could be due to inability of LAB to assimilate inorganic nitrogen sources [62]. Furthermore, de Carvalho et al. [63] also reported that urea was not significant $(p>0.05)$ for the cell growth of LAB, whereby supplementation of urea did not improve the LAB growth.

On the other hand, majority of the studied mineral sources, including $\mathrm{NaOAc}, \mathrm{MgSO}_{4}, \mathrm{MnSO}_{4}$, $\mathrm{ZnSO}_{4}$ and $\mathrm{FeSO}_{4}$ displayed a stimulatory impact on the cell growth of P. acidilactici TP-6, whereas the remaining 3 mineral sources $\left(\mathrm{K}_{2} \mathrm{HPO}_{4}, \mathrm{CuSO}_{4}\right.$ and $\left.\mathrm{KH}_{2} \mathrm{PO}_{4}\right)$ displayed a negative effect. Among the 5 mineral sources with positive effect, $\mathrm{NaOAc}, \mathrm{MgSO}_{4}$ and $\mathrm{MnSO}_{4}$ were highly significant at $\mathrm{p}$-value less than 0.01 and $\mathrm{ZnSO}_{4}$ was significant $(p<0.05)$, whereas $\mathrm{FeSO}_{4}$ did not affect the growth of $P$. acidilactici 
TP-6 significantly ( $p>0.05)$. However, out of the 3 mineral sources that possessed a negative effect, $\mathrm{K}_{2} \mathrm{HPO}_{4}$ and $\mathrm{CuSO}_{4}$ were significant $(p<0.05)$, whereas $\mathrm{KH}_{2} \mathrm{PO}_{4}$ was not significant $(p>0.05)$. Acetate ions are known for its great buffering capacity in maintaining the acidity of the medium. This might be the reason for the strong stimulatory effects of NaOAc on the growth of P. acidilactici TP-6. Since LAB is an acidophilic microorganism, which prefer an acidic growing environment [64], the presence of acetate ion to maintain the acidic growing environment could enhance the growth of LAB [65]. In contrast, the presence of phosphate ion could potentially lead to the elevation of $\mathrm{pH}$, which in turn created an alkaline environment. As a consequence, the growth of acidophiles such as LAB could be retarded [60]. This could explain the inhibitory effect of $\mathrm{KH}_{2} \mathrm{PO}_{4}$ and $\mathrm{K}_{2} \mathrm{HPO}_{4}$ towards the growth of P. acidilactici TP-6. On the other hand, the positive impact of $\mathrm{Mn}^{2+}$ on the cell growth of P. acidilactici TP-6 was in agreement with the results obtained by Tomas et al. [65], whereby the supplementation of $\mathrm{MnSO}_{4}$ in the culture medium had significantly enhanced the growth of Lactobacillus salivarius CRL 1328. Moreover, the growth promoting effect of other mineral ions such as $\mathrm{Mg}^{2+}, \mathrm{Fe}^{2+}, \mathrm{Mg}^{2+}$, $\mathrm{Ca}^{2+}, \mathrm{Co}^{2+}$ and $\mathrm{Cu}^{2+}$ on LAB was also well documented, where a two-fold increment in growth was noted [66]. Despite Foucaud et al. [66] reported that $\mathrm{Cu}^{2+}$ stimulated the growth of LAB, yet results obtained in the current study revealed that $\mathrm{CuSO}_{4}$ exhibited an inhibitory effect on the growth of P. acidilactici TP-6. This might be due to different requirement of metal ions among different LAB strains, implying that the requirement of metal ions could be strain dependent.

Figure 2 shows that Tween 80 affected the growth of $P$. acidilactici TP-6 significantly $(p<0.05)$ in a negative manner, which was contradictory to the findings reported by Li et al. [67], whereby Tween 80 demonstrated a stimulatory effect on the growth of LAB and other microorganisms. On a separate note, the growth of Lactobacillus casei YIT 9018 was not affected significantly $(p>0.05)$ by Tween 80 in the study conducted by $\mathrm{Oh}$ et al. [68]. As a comparison, the vitamin biotin used in this study affected the growth of $P$. acidilactici TP-6 highly significantly $(p<0.01)$ in a negative manner. Similar effect was also observed for the growth of a threonine producer, P. pentosaceus TL-3, where biotin affected the growth of the isolate $P$. pentosaceus TL-3 significantly in a negative manner [60]. However, a contradictory finding was reported by Tripuraneni [69], where the inclusion of biotin in the growth medium of LAB enhanced the bacterial growth. The negative effect of biotin in the current study was most probably due to low biotin requirement of the producer strain. Hence, the abundant biotin content in molasses and organic nitrogen sources was sufficient to fulfil the requirement of P. acidilactici TP-6 [70]. Therefore, further supplementation of biotin contributed to an antagonistic effect.

A number of 17 studied variables were found to affect the production of tryptophan by P. acidilactici TP-6 significantly $(p<0.05)$ in the PBD study (Table 2). However, the use of all the 17 significant variables identified in the PBD for further optimization would result in large number of experimental runs. Hence, a validation test was conducted to verify the significant effects of variables identified in the PBD on tryptophan production by P. acidilactici TP-6 with MRS medium served as control. The medium formulation that used for validation test was described in Section 3.3. The tryptophan production, growth and serine consumption of $P$. acidilactici TP-6 that noted in different formulated media are shown in Table 4. Medium 1 that contained all the variables identified in the PBD recorded the highest tryptophan production of $26.07 \mathrm{mg} / \mathrm{L}$, followed by Medium 5 and Medium 4 with 25.95 $\mathrm{mg} / \mathrm{L}$ and $25.89 \mathrm{mg} / \mathrm{L}$ of net tryptophan produced respectively. However, there was no significant difference $(p>0.05)$ between the net tryptophan produced in Medium 1, Medium 5 and Medium 4. Nevertheless, it is noteworthy that the net tryptophan produced in the 3 media formulations was comparable to the control $(26.81 \mathrm{mg} / \mathrm{L})$, in which they were not significantly different $(p>0.05)$. This implied that Medium 1, 4 and 5 could potentially replace control MRS medium for the production of tryptophan by P. acidilactici TP-6. 
Table 4. Growth, net tryptophan and serine produced by P. acidilactici TP-6 in formulated media.

\begin{tabular}{cccc}
\hline Media & $\begin{array}{c}\text { Cell Population } \\
(\text { Log CFU/mL) }\end{array}$ & $\begin{array}{c}\text { Tryptophan Production } \\
(\mathbf{m g} / \mathrm{L})\end{array}$ & $\begin{array}{c}\text { Serine Consumption } \\
(\mathbf{m g} / \mathrm{L})\end{array}$ \\
\hline $\mathbf{1}$ & $8.95 \pm 0.01^{\mathrm{B}}$ & $26.07 \pm 0.86^{\mathrm{AB}}$ & $9.95 \pm 0.43^{\mathrm{A}}$ \\
$\mathbf{2}$ & $7.98 \pm 0.01^{\mathrm{D}}$ & $25.16 \pm 0.39^{\mathrm{B}}$ & $11.75 \pm 0.86^{\mathrm{A}}$ \\
$\mathbf{3}$ & $8.00 \pm 0.01^{\mathrm{D}}$ & $25.00 \pm 0.20^{\mathrm{B}}$ & $10.09 \pm 0.73^{\mathrm{A}}$ \\
$\mathbf{4}$ & $8.06 \pm 0.01^{\mathrm{C}}$ & $25.89 \pm 1.05^{\mathrm{AB}}$ & $12.43 \pm 0.50^{\mathrm{A}}$ \\
$\mathbf{5}$ & $8.99 \pm 0.02^{\mathrm{B}}$ & $25.95 \pm 0.18^{\mathrm{AB}}$ & $11.40 \pm 0.45^{\mathrm{A}}$ \\
MRS & $9.43 \pm 0.01^{\mathrm{A}}$ & $26.81 \pm 4.86^{\mathrm{A}}$ & $11.47 \pm 1.29^{\mathrm{A}}$ \\
\hline
\end{tabular}

Note: Values are mean \pm standard error of the mean (SEM), $n=3$. Mean \pm SEM within the same column that share similar superscript (A-D) are not significantly different $(p>0.05)$.

In terms of cell growth, the highest cell population of $8.99 \log \mathrm{CFU} / \mathrm{mL}$ was detected in Medium 5, yet it was still significantly lower $(p<0.05)$ in comparison to the control $(9.46 \log \mathrm{CFU} / \mathrm{mL})$. In contrast, the lowest cell growth was observed in Medium 2 (7.98 $\log C F U / \mathrm{mL})$ and Medium 3 (8 $\log \mathrm{CFU} / \mathrm{mL})$, in which they were not significantly different $(p>0.05)$. Moreover, decreasing serine concentration was detected in all formulated media, implying that P. acidilactici TP- 6 might be able to produce tryptophan via biosynthetic pathway by converting the precursor serine to tryptophan.

The results obtained in the validation test showed that Medium 1,4 and 5 were potential medium for tryptophan production by P. acidilactici TP-6 since the highest tryptophan production was noted and there was no significant difference $(p>0.05)$ between the tryptophan yield. However, Medium 1 was excluded due to its multicomponent, leaving Medium 4 and 5 for the consideration as comparable growth medium. Both Medium 4 and 5 differed in their carbon source, whereby Medium 4 contained lactose and Medium 5 contained molasses as carbon source. Despite lactose exhibiting a positive effect, yet the high cost of lactose has rendered its preference as carbon source. Hence, Medium 5 was selected for further optimization, owing to its cost effectiveness as compared to Medium 4. Moreover, the use of molasses, which is an agricultural waste as sole carbon source offer additional advantage by upgrading the agricultural waste to produce value-added product of tryptophan.

\subsection{Steepest Ascent Method}

The vicinity of optimum concentration for each medium component in Medium 5 (Molasses, meat extract, urea and $\mathrm{FeSO}_{4}$ ) were determined through a steepest ascent experiment consisting of 10 steps of ascension. The origin of each medium components in the steepest ascent experiment was fixed based on the high level $(+1)$ of the PBD, whereas the direction and step length of each variable was determined based on the model of PBD (Equation (3)). According to the first-order model obtained in the PBD, meat extract, urea and $\mathrm{FeSO}_{4}$ which exerted a positive effect were adjusted towards the direction of ascension since increasing the concentration of these variables would improve the production of tryptophan. In contrast, molasses which wielded a negative effect was adjusted towards the direction of dissension, as reducing the concentration of a negative variable would enhance the tryptophan production. Meanwhile, the largest coefficient which in this case, the meat extract was used as reference to compute the step length of urea and $\mathrm{FeSO}_{4}$. Hence, for every $50 \%$ increment of the meat extract concentration, the concentration of urea and $\mathrm{FeSO}_{4}$ were increased by $20 \%$ and $28.5 \%$ respectively. At the meantime, the concentration of molasses was reduced by $10 \%$ at each run.

The cell population, net tryptophan and serine (precursor of tryptophan) produced by P. acidilactici TP-6 in the steepest ascent experiment are displayed in Table 5. It was clearly evidenced that the net tryptophan produced was increasing progressively along the path of steepest ascent from the origin $(27 \mathrm{mg} / \mathrm{L})$ and achieved maximum tryptophan production in run $5(69.05 \mathrm{mg} / \mathrm{L})$, indicating that the net tryptophan produced was enhanced approximately 2.5 folds after the optimization by steepest ascent procedure. Nevertheless, the net tryptophan produced began to decline beyond run 5 , implying that further increasing the concentration of meat extract, urea and $\mathrm{FeSO}_{4}$ or reducing the concentration of molasses exerted inhibitory effect on the production of tryptophan by P. acidilactici TP- 6 . Furthermore, 
the net tryptophan produced in run 5 was significantly higher $(p<0.05)$ than control MRS medium, inferring that the formulated medium by steepest ascent method could be used as an alternative medium for the production of tryptophan by P. acidilactici TP-6.

Similar trend was observed for the cell population of P. acidilactici TP-6, whereby the cell growth increased from the origin $(9.10 \log \mathrm{CFU} / \mathrm{mL})$ and the highest cell population was detected in run $5(9.24$ $\log \mathrm{CFU} / \mathrm{mL})$. Thereafter, the cell growth remained unchanged up to run $7(9.25 \log \mathrm{CFU} / \mathrm{mL})$ and the cell population decreased slowly as the concentration of medium components increased beyond run 7 . Merely $8.77 \log \mathrm{CFU} / \mathrm{mL}$ of cell population was noted at run 11 . However, the cell population recorded in the control MRS medium $(9.37 \log \mathrm{CFU} / \mathrm{mL})$ was still significantly higher $(p<0.05)$ than the cell population detected in different media formulations in the steepest ascent experiment. Interestingly, reduced serine content was detected in all the experimental runs, implying that P. acidilactici TP-6 might produce tryptophan via biosynthetic pathway, whereby serine precursor was converted to tryptophan, thereby resulted in a decreasing serine content. The concentrations of different medium components of run 5 (molasses, $15.04 \mathrm{~g} / \mathrm{L}$; meat extract, $24 \mathrm{~g} / \mathrm{L}$; urea, $5.4 \mathrm{~g} / \mathrm{L} ; \mathrm{FeSO}_{4}, 0.022 \mathrm{~g} / \mathrm{L}$ ) were subsequently employed as the center point for further optimization by using CCD.

Table 5. Cell population, tryptophan production and serine consumption of P. acidilactici TP-6 for different media formulation in the steepest ascent experiment.

\begin{tabular}{cccc}
\hline Run & $\begin{array}{c}\text { Cell Population } \\
(\mathbf{l o g} \text { CFU/mL) }\end{array}$ & $\begin{array}{c}\text { Tryptophan Production } \\
(\mathbf{m g} / \mathbf{L})\end{array}$ & $\begin{array}{c}\text { Serine Consumption } \\
(\mathbf{m g} / \mathbf{L})\end{array}$ \\
\hline $\mathbf{1}$ & $9.10 \pm 0.02^{\mathrm{D}}$ & $27.73 \pm 0.04^{\mathrm{G}}$ & $8.72 \pm 0.21^{\mathrm{D}}$ \\
$\mathbf{2}$ & $9.10 \pm 0.01^{\mathrm{D}}$ & $35.79 \pm 0.28^{\mathrm{F}}$ & $9.05 \pm 0.35^{\mathrm{DE}}$ \\
$\mathbf{3}$ & $9.14 \pm 0.01^{\mathrm{CD}}$ & $42.64 \pm 0.40^{\mathrm{E}}$ & $9.24 \pm 0.39^{\mathrm{DE}}$ \\
$\mathbf{4}$ & $9.15 \pm 0.01^{\mathrm{C}}$ & $55.54 \pm 0.36^{\mathrm{C}}$ & $8.93 \pm 0.01^{\mathrm{DE}}$ \\
$\mathbf{5}$ & $9.24 \pm 0.01^{\mathrm{B}}$ & $69.05 \pm 0.55^{\mathrm{A}}$ & $9.53 \pm 0.09^{\mathrm{DEF}}$ \\
$\mathbf{6}$ & $9.24 \pm 0.01^{\mathrm{B}}$ & $59.84 \pm 0.68^{\mathrm{B}}$ & $10.15 \pm 0.12^{\mathrm{F}}$ \\
$\mathbf{7}$ & $9.25 \pm 0.01^{\mathrm{B}}$ & $51.67 \pm 0.92^{\mathrm{D}}$ & $9.65 \pm 0.21^{\mathrm{EF}}$ \\
$\mathbf{8}$ & $9.18 \pm 0.01^{\mathrm{C}}$ & $43.77 \pm 0.23^{\mathrm{E}}$ & $9.00 \pm 0.11^{\mathrm{DE}}$ \\
$\mathbf{9}$ & $9.16 \pm 0.01^{\mathrm{C}}$ & $36.74 \pm 0.91^{\mathrm{F}}$ & $7.56 \pm 0.16^{\mathrm{C}}$ \\
$\mathbf{1 0}$ & $9.04 \pm 0.01^{\mathrm{E}}$ & $21.98 \pm 0.38^{\mathrm{H}}$ & $4.21 \pm 0.10^{\mathrm{A}}$ \\
$\mathbf{1 1}$ & $8.77 \pm 0.03^{\mathrm{F}}$ & $10.02 \pm 0.07^{\mathrm{I}}$ & $5.11 \pm 0.45^{\mathrm{B}}$ \\
$\mathbf{M R S}$ & $9.37 \pm 0.01^{\mathrm{A}}$ & $27.69 \pm 0.15^{\mathrm{G}}$ & $7.69 \pm 0.37^{\mathrm{C}}$ \\
\hline
\end{tabular}

Note: Values are mean \pm standard error of the mean (SEM), $n=3$. Mean \pm SEM within the same column that share similar superscript (A-I) are not significantly different $(p>0.05)$.

\subsection{Central Composite Design}

The concentrations of molasses, meat extract, urea and $\mathrm{FeSO}_{4}$ were further optimized by using CCD of Response Surface Methodology (RSM) after the steepest ascent procedure. The concentration of molasses, meat extract, urea and $\mathrm{FeSO}_{4}$ were assigned to five levels-high level (+1), low level $(-1)$, central point $(0)$ and 2 axial points $( \pm \alpha)$. Hence, a total of 30 experimental runs were suggested by the CCD and their corresponding experimental and predicted net tryptophan produced are shown in Table 6 respectively. In general, the highest net tryptophan produced was detected in runs 25-30, where all the variables were set at the center point and the respective net tryptophan produced was up to $70 \mathrm{mg} / \mathrm{L}$, followed by run $24(66.07 \mathrm{mg} / \mathrm{L})$ which constituted of molasses, meat extract and urea that fixed at center point, while the $\mathrm{FeSO}_{4}$ was supplemented at +2 level. The net tryptophan production recorded in runs $25-30$ were significantly higher $(p<0.05)$ as compared to the other experiment runs, as well as the control MRS medium $(28.18 \mathrm{mg} / \mathrm{L})$. 
Table 6. Central Composite Design (CCD) matrix with coded value and their corresponding experimental and predicted tryptophan production by P. acidilactici TP-6.

\begin{tabular}{|c|c|c|c|c|c|c|}
\hline \multirow{2}{*}{ Std Run } & \multirow{2}{*}{$\mathbf{A}$} & \multirow{2}{*}{ B } & \multirow{2}{*}{$\mathrm{C}$} & \multirow{2}{*}{$\mathbf{D}$} & \multicolumn{2}{|c|}{ Tryptophan Production (mg/L) } \\
\hline & & & & & Experimental & Predicted * \\
\hline 1 & -1 & -1 & -1 & -1 & $56.24 \pm 0.04 \mathrm{JKL}$ & 56.86 \\
\hline 2 & 1 & -1 & -1 & -1 & $54.33 \pm 0.20^{\mathrm{N}}$ & 54.44 \\
\hline 3 & -1 & 1 & -1 & -1 & $53.23 \pm 0.14^{\mathrm{O}}$ & 53.54 \\
\hline 4 & 1 & 1 & -1 & -1 & $54.49 \pm 0.26^{\mathrm{N}}$ & 54.72 \\
\hline 5 & -1 & -1 & 1 & -1 & $60.62 \pm 0.17 \mathrm{G}$ & 60.38 \\
\hline 6 & 1 & -1 & 1 & -1 & $57.12 \pm 0.23 \mathrm{IJK}$ & 57.64 \\
\hline 7 & -1 & 1 & 1 & -1 & $59.14 \pm 0.32 \mathrm{H}$ & 59.38 \\
\hline 8 & 1 & 1 & 1 & -1 & $59.69 \pm 0.26^{\mathrm{GH}}$ & 60.24 \\
\hline 9 & -1 & -1 & -1 & 1 & $63.25 \pm 0.35^{\mathrm{E}}$ & 63.20 \\
\hline 10 & 1 & -1 & -1 & 1 & $56.32 \pm 0.44 \mathrm{JKL}$ & 56.78 \\
\hline 11 & -1 & 1 & -1 & 1 & $59.25 \pm 0.25^{\mathrm{H}}$ & 59.44 \\
\hline 12 & 1 & 1 & -1 & 1 & $55.89 \pm 0.85^{\mathrm{LM}}$ & 56.62 \\
\hline 13 & -1 & -1 & 1 & 1 & $64.47 \pm 0.40^{\mathrm{D}}$ & 64.92 \\
\hline 14 & 1 & -1 & 1 & 1 & $58.01 \pm 0.56^{\mathrm{I}}$ & 58.18 \\
\hline 15 & -1 & 1 & 1 & 1 & $63.13 \pm 0.68^{\mathrm{EF}}$ & 63.48 \\
\hline 16 & 1 & 1 & 1 & 1 & $60.25 \pm 0.44 \mathrm{GH}$ & 60.34 \\
\hline 17 & -2 & 0 & 0 & 0 & $62.23 \pm 0.29 \mathrm{EF}$ & 61.88 \\
\hline 18 & 2 & 0 & 0 & 0 & $57.19 \pm 0.33 \mathrm{IJ}$ & 56.32 \\
\hline 19 & 0 & -2 & 0 & 0 & $56.83 \pm 0.12^{\mathrm{IJKL}}$ & 56.36 \\
\hline 20 & 0 & 2 & 0 & 0 & $55.95 \pm 0.13 \mathrm{KLM}$ & 55.20 \\
\hline 21 & 0 & 0 & -2 & 0 & $55.03 \pm 0.22 \mathrm{MN}$ & 54.28 \\
\hline 22 & 0 & 0 & 2 & 0 & $61.99 \pm 0.42 \mathrm{~F}$ & 61.52 \\
\hline 23 & 0 & 0 & 0 & -2 & $59.66 \pm 0.27 \mathrm{GH}$ & 59.04 \\
\hline 24 & 0 & 0 & 0 & 2 & $66.07 \pm 0.05^{C}$ & 65.48 \\
\hline 25 & 0 & 0 & 0 & 0 & $69.33 \pm 0.10 \mathrm{AB}$ & 69.42 \\
\hline 26 & 0 & 0 & 0 & 0 & $69.55 \pm 0.31 \mathrm{AB}$ & 69.42 \\
\hline 27 & 0 & 0 & 0 & 0 & $70.22 \pm 0.07^{\mathrm{A}}$ & 69.42 \\
\hline 28 & 0 & 0 & 0 & 0 & $68.85 \pm 0.39^{B}$ & 69.42 \\
\hline 29 & 0 & 0 & 0 & 0 & $69.69 \pm 0.55 \mathrm{AB}$ & 69.42 \\
\hline 30 & 0 & 0 & 0 & 0 & $68.88 \pm 0.94^{\mathrm{B}}$ & 69.42 \\
\hline MRS & - & - & - & - & $28.18 \pm 0.12^{\mathrm{P}}$ & - \\
\hline
\end{tabular}

Note: Values are mean \pm standard error of mean (SEM), $n=3$. Mean \pm SEM within the same column that share similar superscript (A-P) are not significantly different $(p>0.05)$. * Predicted tryptophan production was calculated based on Equation (3).

The data were then analyzed with different regression models to investigate which model is best fitted to describe the relation between the variables and the production of tryptophan produced by P. acidilactici TP-6 as presented in Table 7. Based on the ANOVA table, it is clearly evidenced that the data were best fitted to a quadratic polynomial model. Among the 4 tested polynomial models, only the quadratic model was significant $(p<0.05)$, whereas the other polynomial models were insignificant $(p>0.05)$. Additionally, the quadratic model was highly predictive owing to its exceptionally high adjusted $R^{2}$ value (0.9837) and high predicted $R^{2}$ value (0.9586), which was not observed for other polynomial models. Furthermore, the p-value of the lack of fit test of the quadratic model (0.2196) implied that the lack of fit was not significant $(p>0.05)$ and the model can be used to explain and predict the response, which in this case the tryptophan production. This was evidenced by the good agreement between the predicted and experimental tryptophan production as presented in Table 6 . Unlike the cubic polynomial model, the presence of aliased effects between the variables was not detected in the quadratic model. Hence, the production of tryptophan by P. acidilactici TP- 6 can be best represented by the quadratic model. The following quadratic Equation (3) elucidated the effects of molasses (A), meat extract (B), urea (C) and $\mathrm{FeSO}_{4}$ (D) on tryptophan production by P. acidilactici TP-6 $(\mathrm{Y})$ in terms of coded symbols (A-D): 


$$
\begin{gathered}
\mathrm{Y}=69.42-1.39 \mathrm{~A}-0.29 \mathrm{~B}+1.81 \mathrm{C}+1.61 \mathrm{D}+0.9 \mathrm{AB}-0.084 \mathrm{AC}-1.00 \mathrm{AD}+0.58 \mathrm{BC}- \\
0.11 \mathrm{BD}-0.45 \mathrm{CD}-2.58 \mathrm{~A}^{2}-3.41 \mathrm{~B}^{2}-2.88 \mathrm{C}^{2}-1.79 \mathrm{D}^{2}
\end{gathered}
$$

Table 7. ANOVA of regression model for tryptophan production by P. acidilactici TP-6.

\begin{tabular}{cccccc}
\hline \multirow{2}{*}{ Source } & Sequential & Lack of Fit & Adjusted & Predicted & \\
\cline { 2 - 4 } & $\boldsymbol{p}$-Value & $\boldsymbol{p}$-Value & R-Squared & R-Squared & \\
\hline Linear & 0.1492 & $<0.0001$ & 0.1059 & 0.0576 & \\
Crossproduct & 0.9724 & $<0.0001$ & -0.1063 & -0.3333 & \\
Quadratic & $<0.0001$ & 0.2196 & 0.9837 & 0.9586 & Suggested \\
Cubic & 0.9875 & 0.0265 & 0.9709 & 0.2223 & Aliased \\
\hline
\end{tabular}

The statistical significance of the quadratic model and the variables were evaluated by F-test and the ANOVA is presented in Table 8. The low p-value of the model $(<0.01)$ implied that the model was highly significant $(p<0.01)$ and it was highly unlikely ( $>99 \%$ confidence) that the large F-value of the model this large was attributed to noise. Moreover, the model exhibited great predictive strength and was able to explain $99.2 \%$ of variation in response due to its high $\mathrm{R}^{2}$ value (0.9916). Additionally, the "predicted $R^{2 \text { " }}\left(0\right.$. 9586) and the "adjusted $R^{2 \text { " }}(0.9837)$ values were in reasonable agreement (difference $<0.2$ ), implying the great correlation between experimental and predicted values and the suggested model was significant. This was further supported by the insignificant lack of fit $(p>0.05)$, which was indicated by the high p-value of lack of fit test (0.22). Furthermore, the model was suitable for navigating the design space owing to its adequate signal to noise ratio which was reflected by the high adequate precision value (33.028) that was much greater than the threshold value of $\mathrm{f} 4$. On the other hand, the ANOVA results revealed that all the linear coefficients and quadratic coefficients affected tryptophan production significantly $(p<0.01)$ except the linear coefficient of meat extract (B). Furthermore, the interaction coefficient $\mathrm{AB}, \mathrm{AD}, \mathrm{BC}$ and $\mathrm{BC}$ were found to contribute significantly $(p<0.05)$ to the production of tryptophan by P. acidilactici TP -6 .

\begin{tabular}{|c|c|c|c|c|c|c|}
\hline Source & Sum of Squares & df & $\begin{array}{l}\text { Mean } \\
\text { Square }\end{array}$ & F-Value & $\begin{array}{c}p \text {-value } \\
\text { Prob > F }\end{array}$ & \\
\hline Model & 814.96 & 14 & 58.21 & 126.07 & $<0.01$ & significant \\
\hline $\mathrm{A}$ & 46.16 & 1 & 46.16 & 99.97 & $<0.01$ & significant \\
\hline B & 2.08 & 1 & 2.08 & 4.51 & 0.05 & \\
\hline $\mathrm{C}$ & 78.3 & 1 & 78.3 & 169.58 & $<0.01$ & significant \\
\hline $\mathrm{D}$ & 61.84 & 1 & 61.84 & 133.92 & $<0.01$ & significant \\
\hline $\mathrm{AB}$ & 12.86 & 1 & 12.86 & 27.84 & $<0.01$ & significant \\
\hline $\mathrm{AC}$ & 0.11 & 1 & 0.11 & 0.24 & 0.63 & \\
\hline $\mathrm{AD}$ & 16.07 & 1 & 16.07 & 34.8 & $<0.01$ & significant \\
\hline $\mathrm{BC}$ & 5.36 & 1 & 5.36 & 11.62 & $<0.01$ & significant \\
\hline $\mathrm{BD}$ & 0.2 & 1 & 0.2 & 0.42 & 0.53 & \\
\hline CD & 3.17 & 1 & 3.17 & 6.86 & 0.02 & significant \\
\hline$A^{2}$ & 182.37 & 1 & 182.37 & 394.96 & $<0.01$ & significant \\
\hline $\mathrm{B}^{2}$ & 318.65 & 1 & 318.65 & 690.1 & $<0.01$ & significant \\
\hline$C^{2}$ & 227.15 & 1 & 227.15 & 491.94 & $<0.01$ & significant \\
\hline $\mathrm{D}^{2}$ & 87.9 & 1 & 87.9 & 190.37 & $<0.01$ & significant \\
\hline Residual & 6.93 & 15 & 0.46 & & & \\
\hline Lack of Fit & 5.57 & 10 & 0.56 & 2.06 & 0.22 & not significant \\
\hline Pure Error & 1.35 & 5 & 0.27 & & & \\
\hline Cor Total & 821.88 & 29 & & & & \\
\hline
\end{tabular}

Table 8. ANOVA for quadratic model of tryptophan production by P. acidilactici TP-6. 
The relationship between the coded variables and response was subsequently examined by constructing the three-dimensional surface plots as shown in Figures 3-8. The interaction between molasses and meat extract is depicted in Figure 3 by maintaining the concentration of urea and $\mathrm{FeSO}_{4}$ at $5.4 \mathrm{~g} / \mathrm{L}$ and $0.022 \mathrm{~g} / \mathrm{L}$, respectively, as the center point. Increased tryptophan production was noted with increased concentration of meat extract and molasses. The highest net tryptophan produced was detected when molasses and meat extract were both between the levels of -1 to +1 . The synergistic effect of molasses and meat extract (AB) was highly significant as reflected by the p-value of less than 0.01 (Table 8). Figure 4 illustrates the response surface of tryptophan production with respect to molasses and urea by keeping the concentration of meat extract and $\mathrm{FeSO}_{4}$ at the center point $(24 \mathrm{~g} / \mathrm{L}$, $0.022 \mathrm{~g} / \mathrm{L}$ ). Increasing concentration of both molasses and urea resulted in higher net tryptophan produced. The highest net tryptophan produced was detected when molasses was in the range of -1 to 0 and urea was between 0 to +1 . However, the tryptophan production was retarded when the concentration of molasses and urea was changed beyond the above-mentioned boundaries. The p-value of the interaction effect of AC (0.63) indicated that it was not significant (Table 8).

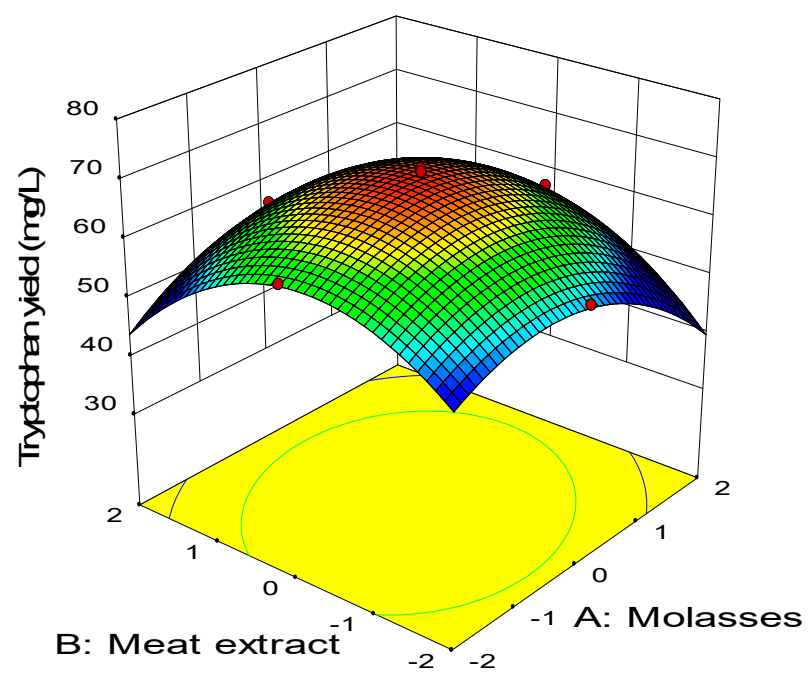

Figure 3. Response surface of tryptophan production by P. acidilactici TP-6 as a function of molasses and meat extract.

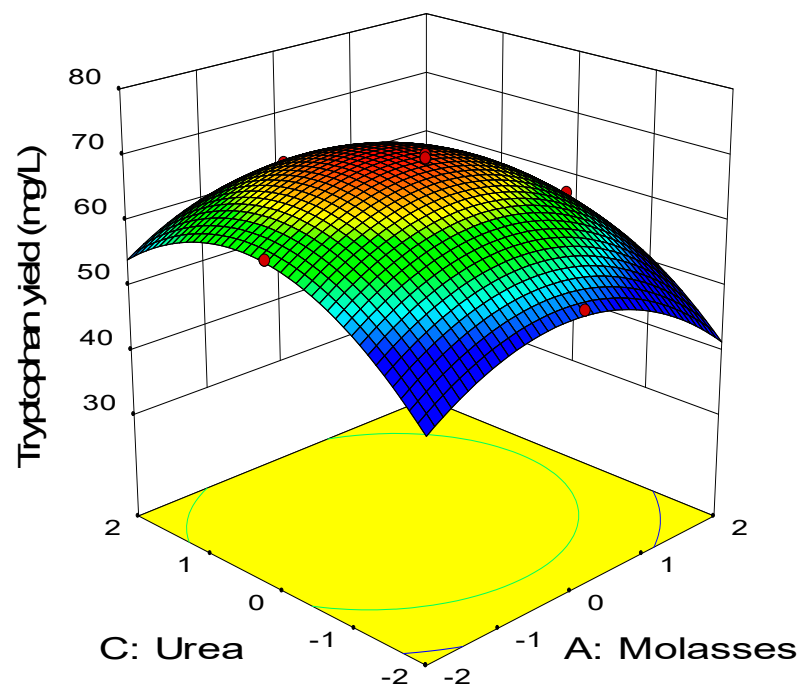

Figure 4. Response surface of tryptophan production by P. acidilactici TP-6 as a function of molasses and urea. 
Figure 5 illustrates the combined effect between molasses and $\mathrm{FeSO}_{4}$ while keeping the level of meat extract and urea at $24 \mathrm{~g} / \mathrm{L}$ and $5.4 \mathrm{~g} / \mathrm{L}$, respectively, which were the center points. Similarly, increasing concentration of both molasses and $\mathrm{FeSO}_{4}$ enhanced the net tryptophan produced. The highest net tryptophan production was detected when molasses was at the center point and $\mathrm{FeSO}_{4}$ was between the center point $(0)$ and high level $(+1)$. ANOVA (Table 8 ) revealed that the interaction effect between molasses and $\mathrm{FeSO}_{4}(\mathrm{AD})$ was highly significantly $(p<0.01)$ on the net tryptophan produced. Figure 6 shows the interaction between the meat extract and urea, in which the concentration of $\mathrm{FeSO}_{4}$ and molasses were maintained at $0.022 \mathrm{~g} / \mathrm{L}$ and $15.04 \mathrm{~g} / \mathrm{L}$, respectively, which were the center points. Increasing concentration of meat extract and urea improved the net tryptophan production by P. acidilactici TP-6. The highest tryptophan production was detected when both urea and meat extract were between low level $(-1)$ and high level $(+1)$. Increasing or decreasing the concentration of either meat extract or urea beyond these boundaries reduced the net tryptophan produced substantially. Based on Table 8 , the interaction effect of meat extract and urea (BC) was highly significant $(p<0.01)$.

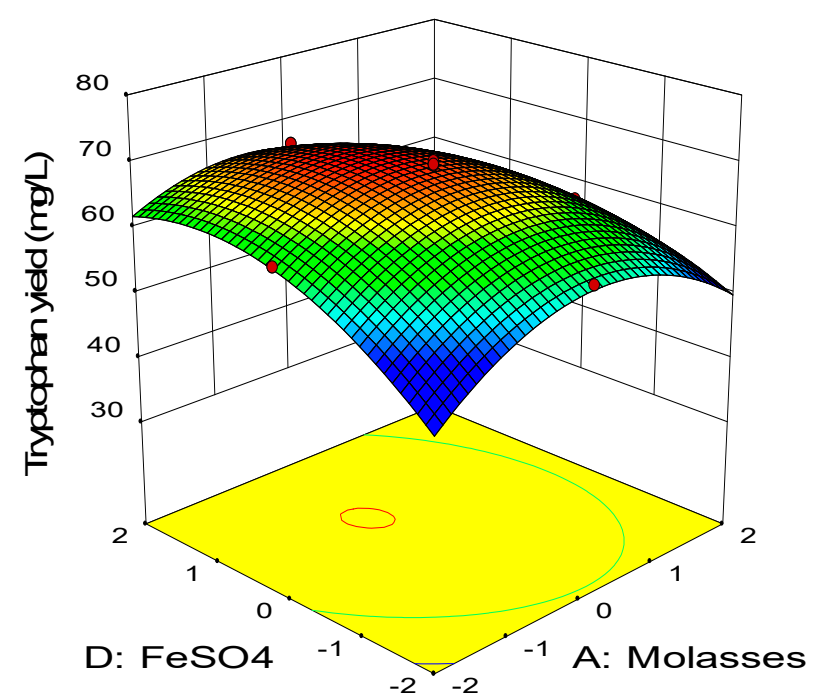

Figure 5. Response surface of tryptophan production by P. acidilactici TP-6 as a function of molasses and $\mathrm{FeSO}_{4}$.

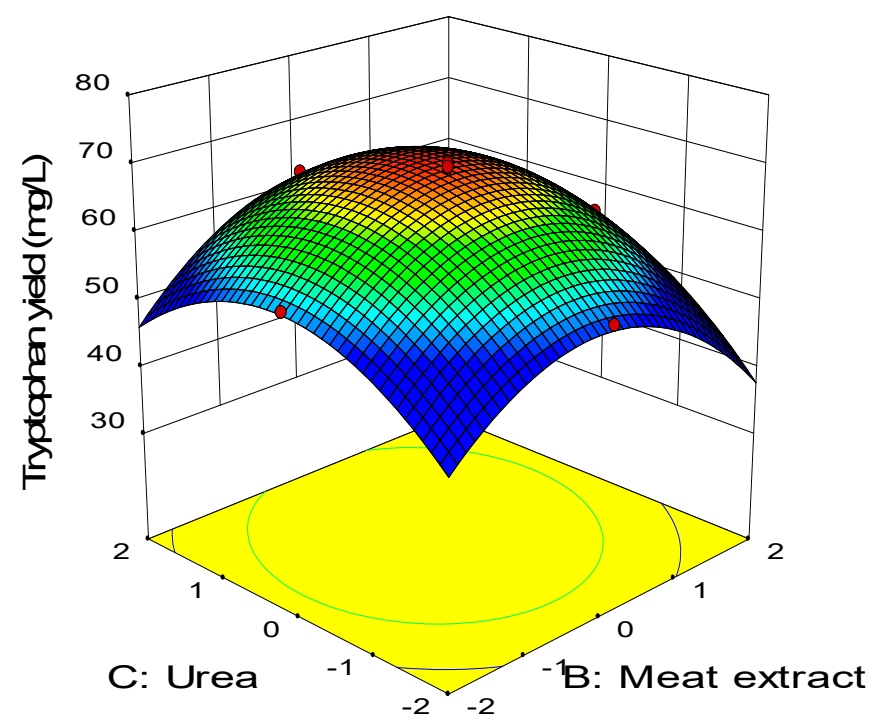

Figure 6. Response surface of tryptophan production by P. acidilactici TP-6 as a function of meat extract and urea. 
Figure 7 depicts the three-dimensional surface plot of net tryptophan produced as a function of meat extract and $\mathrm{FeSO}_{4}$ while keeping the concentration of molasses and urea at the center point $(15.04 \mathrm{~g} / \mathrm{L}, 5.4 \mathrm{~g} / \mathrm{L})$. Increasing concentration of both $\mathrm{FeSO}_{4}$ and meat extract elevated the net tryptophan produced. The highest production was observed when meat extract was in the range of -1 to +1 while the $\mathrm{FeSO}_{4}$ may vary between -1 to +2 . The synergistic effect of meat extract and $\mathrm{FeSO}_{4}(\mathrm{BD})$ was insignificant $(p>0.05)$ as reflected by the high $p$-value (0.53) in the ANOVA analysis (Table 8$)$. On the other hand, the combined effect of urea and $\mathrm{FeSO}_{4}$ is illustrated in Figure 8, in which the concentration of meat extract and molasses was kept constant at the center point $(24 \mathrm{~g} / \mathrm{L}, 15.04 \mathrm{~g} / \mathrm{L})$. Enhanced production of tryptophan was noted upon increment of the urea and $\mathrm{FeSO}_{4}$ concentration. The highest net tryptophan production was observed when urea was supplemented between the range of 0 to +1 and $\mathrm{FeSO}_{4}$ was in the range of -1 up to +2 . The $p$-value of the interaction coefficient $\mathrm{CD}(0.02)$ revealed that it contributed significantly $(p<0.05)$ to the production of tryptophan by P. acidilactici TP- 6 .

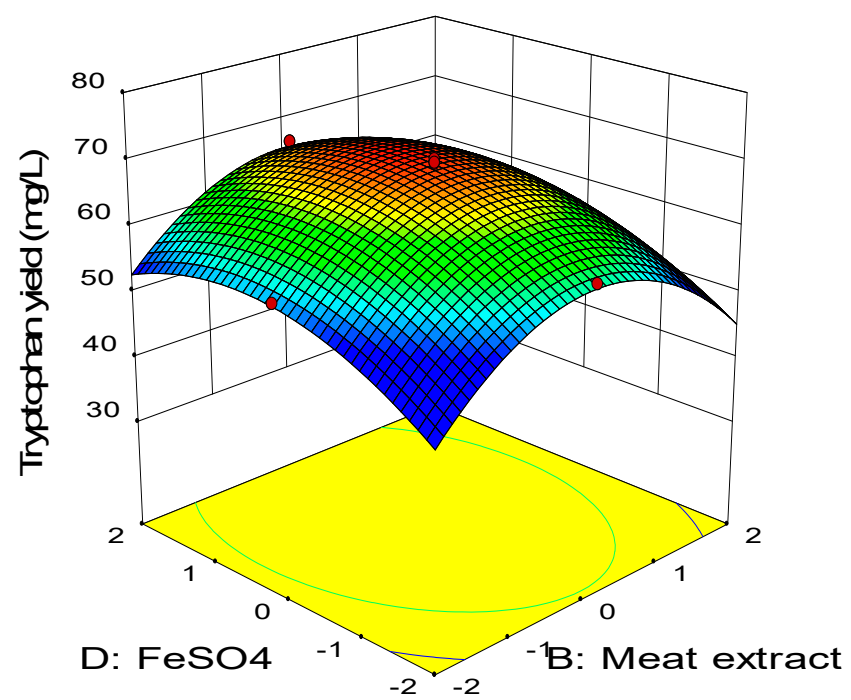

Figure 7. Response surface of tryptophan production by P. acidilactici TP-6 as a function of meat extract and $\mathrm{FeSO}_{4}$.

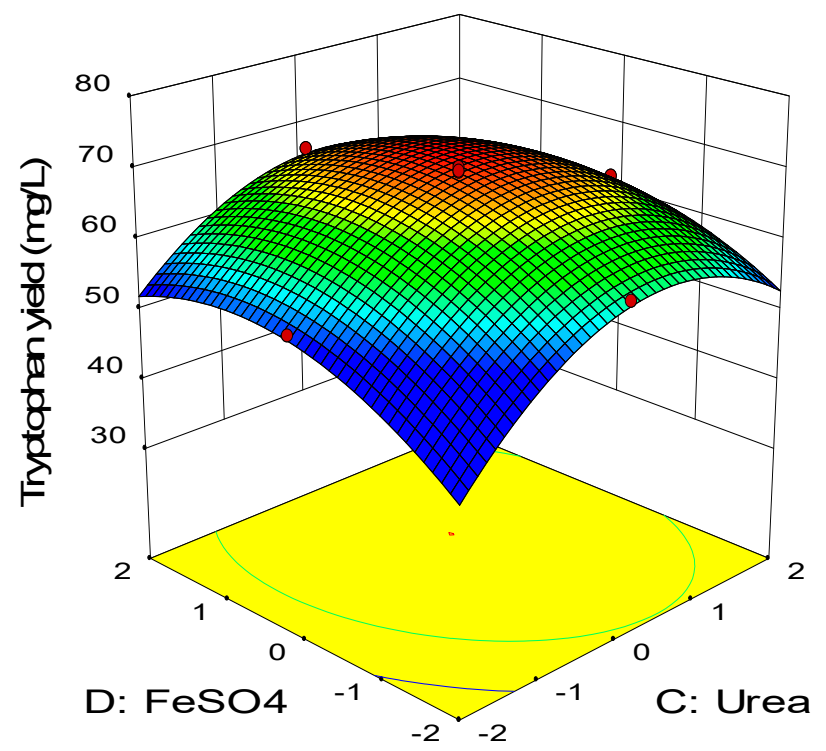

Figure 8. Response surface of tryptophan production by P. acidilactici TP-6 as a function of urea and $\mathrm{FeSO}_{4}$. 
By considering criteria such that the response is maximized and all the variables were in the range from -1 to +1 , the optimum concentration of molasses $(14.06 \mathrm{~g} / \mathrm{L})$, meat extract $(23.68 \mathrm{~g} / \mathrm{L})$, urea $(5.56 \mathrm{~g} / \mathrm{L})$ and $\mathrm{FeSO}_{4}(0.024 \mathrm{~g} / \mathrm{L})$ were revealed with a predicted tryptophan production of $70.38 \mathrm{mg} / \mathrm{L}$. Upon validation by cultivating P. acidilactici TP-6 in the optimized medium proposed by the model, up to $68.05 \mathrm{mg} / \mathrm{L}$ of tryptophan production was achieved by P. acidilactici TP-6 experimentally. Despite the experimental tryptophan production being slightly lower than the predicted value; however, they were not significantly different $(p>0.05)$. The tryptophan production recorded by P. acidilactici TP-6 in the optimized medium $(68.05 \mathrm{mg} / \mathrm{L})$ was enhanced by $150 \%$ in comparison to the control MRS medium $(26.45 \mathrm{mg} / \mathrm{L})$. Meanwhile, the tryptophan productivity by the producer strain in the optimized medium $(3.40 \mathrm{mg} / \mathrm{L} / \mathrm{h})$ was improved by approximately 2.5 folds as compared to the control MRS medium $(1.32 \mathrm{mg} / \mathrm{L} / \mathrm{h})$. In comparison with the production of tryptophan by L. delbrueckii subsp. bulgaricus $(7.4 \mathrm{mg} / \mathrm{L})$ in a study conducted by Simova et al. [71], P. acidilactici TP-6 produced a more than 9 times higher amount of tryptophan by using optimized medium as noted in the current study. Moreover, less than $2 \mathrm{mg} / \mathrm{L}$ of tryptophan production was reported for Lactobacilli [24], which was tremendously lower than the tryptophan production reported in the present study. Thus, the findings obtained in this study revealed that a rapid evaluation and effective optimization of medium composition governing tryptophan production by P. acidilactici TP-6 were feasible via statistical approaches, whereby the production of tryptophan demonstrated by P. acidilactici TP-6 in the optimized medium was much higher than those reported in several studies using a non-optimized medium, inferring the feasibility of utilizing P. acidilactici TP-6 as a food-grade alternative producer for the production of tryptophan. Additionally, the current findings revealed the potential of utilizing LAB as a safer alternative tryptophan producer, as well as providing basis for the exploitation of various amino acid productions by LAB in the future.

\section{Materials and Methods}

\subsection{Inoculum Preparation}

P. acidilactici TP-6 that was previously isolated from Malaysian fermented food, Tempeh [72], was employed as the producer strain for tryptophan production in this study. The strain was cultivated and preserved as described by Kareem et al. [73]. The inoculum preparation was performed as described by Lim et al. [60].

\subsection{Experimental Design}

PBD was first employed to elucidate the significance of medium components on the production of tryptophan by P. acidilactici TP-6, followed by validation of the effects of significant variables that were most crucial for tryptophan production by P. acidilactici TP-6. The range of optimum concentration for each significant varieble was subsequently estimated by using steepest ascent method, followed by the optimization of the concentrations of medium components for the production of tryptophan by P. acidilactici TP-6 via CCD of RSM.

\subsection{Plackett-Burman Design}

The nutritional requirement of $P$. acidilactici TP-6 for tryptophan production was evaluated by using PBD [74]. The design of experiment and statistical analysis of data were performed by using Design Expert statistical software version 9.0.6.2 (State-Ease Inc, Minneapolis, MN, USA). A number of 22 medium components which might affect amino acid production were selected based on published reports and control MRS medium composition and evaluated in the current study by assigning each variable at two distinct levels, namely low level (-1) and high level (+1) as presented in Table 9 [60]. 
Table 9. Coded and real values of variables selected in PBD for tryptophan production by P. acidilactici TP-6.

\begin{tabular}{|c|c|c|c|c|}
\hline \multirow{2}{*}{ Variables } & \multirow{2}{*}{ Symbol Code } & \multirow{2}{*}{ Unit } & \multicolumn{2}{|c|}{ Coded Values } \\
\hline & & & -1 & +1 \\
\hline Glucose & A & $\mathrm{g} / \mathrm{L}$ & 0 & 20 \\
\hline Sucrose & $\mathrm{B}$ & $\mathrm{g} / \mathrm{L}$ & 0 & 17.69 \\
\hline Fructose & $\mathrm{C}$ & $\mathrm{g} / \mathrm{L}$ & 0 & 19.08 \\
\hline Lactose & $\mathrm{D}$ & $\mathrm{g} / \mathrm{L}$ & 0 & 18.86 \\
\hline Molasses & $\mathrm{E}$ & $\mathrm{g} / \mathrm{L}$ & 0 & 25.08 \\
\hline Yeast extract & $\mathrm{F}$ & $\mathrm{g} / \mathrm{L}$ & 0 & 4 \\
\hline Peptone & G & $\mathrm{g} / \mathrm{L}$ & 0 & 10 \\
\hline Meat extract & $\mathrm{H}$ & $\mathrm{g} / \mathrm{L}$ & 0 & 8 \\
\hline $\mathrm{K}_{2} \mathrm{HPO}_{4}$ & $\mathrm{~J}$ & $\mathrm{~g} / \mathrm{L}$ & 0 & 2 \\
\hline $\mathrm{KH}_{2} \mathrm{PO}_{4}$ & $\mathrm{~K}$ & $\mathrm{~g} / \mathrm{L}$ & 0 & 2 \\
\hline Urea & $\mathrm{L}$ & $\mathrm{g} / \mathrm{L}$ & 0 & 3 \\
\hline $\mathrm{NH}_{4} \mathrm{NO}_{3}$ & M & $\mathrm{g} / \mathrm{L}$ & 0 & 5 \\
\hline$\left(\mathrm{NH}_{4}\right)_{2} \mathrm{SO}_{4}$ & $\mathrm{~N}$ & $\mathrm{~g} / \mathrm{L}$ & 0 & 5 \\
\hline$\left(\mathrm{NH}_{4}\right)_{2} \mathrm{HC}_{6} \mathrm{H}_{5} \mathrm{O}_{7}$ & $\mathrm{O}$ & $\mathrm{g} / \mathrm{L}$ & 0 & 2 \\
\hline NaOAc & $\mathrm{P}$ & $\mathrm{g} / \mathrm{L}$ & 0 & 5 \\
\hline $\mathrm{MgSO}_{4}$ & Q & $\mathrm{g} / \mathrm{L}$ & 0 & 0.2 \\
\hline $\mathrm{MnSO}_{4}$ & $\mathrm{R}$ & $\mathrm{g} / \mathrm{L}$ & 0 & 0.04 \\
\hline Tween 80 & S & $\mathrm{mL} / \mathrm{L}$ & 0 & 1 \\
\hline $\mathrm{FeSO}_{4}$ & $\mathrm{~T}$ & $\mathrm{~g} / \mathrm{L}$ & 0 & 0.01 \\
\hline $\mathrm{ZnSO}_{4}$ & $\mathrm{U}$ & $\mathrm{g} / \mathrm{L}$ & 0 & 0.01 \\
\hline $\mathrm{CuSO}_{4}$ & $\mathrm{~V}$ & $\mathrm{~g} / \mathrm{L}$ & 0 & 0.01 \\
\hline Biotin & W & $\mathrm{g} / \mathrm{L}$ & 0 & 0.06 \\
\hline
\end{tabular}

Table 10 presents matrixes of the PBD constituting of 24 experimental runs as suggested by the software.

Table 10. PBD matrix for 22 variables with coded values for tryptophan production by P. acidilactici TP-6.

\begin{tabular}{|c|c|c|c|c|c|c|c|c|c|c|c|c|c|c|c|c|c|c|c|c|c|c|c|}
\hline $\begin{array}{l}\text { Std } \\
\text { Run }\end{array}$ & A & B & C & D & $\mathrm{E}$ & $\mathbf{F}$ & G & $\mathbf{H}$ & $\mathbf{J}$ & $\mathbf{K}$ & L & $\mathbf{M}$ & $\mathbf{N}$ & O & $\mathbf{P}$ & $\mathbf{Q}$ & $\mathbf{R}$ & S & $\mathrm{T}$ & $\mathbf{U}$ & V & W & $X$ \\
\hline 1 & 1 & 1 & 1 & 1 & 1 & -1 & 1 & -1 & 1 & 1 & -1 & -1 & 1 & 1 & -1 & -1 & 1 & -1 & 1 & -1 & -1 & -1 & -1 \\
\hline 2 & -1 & 1 & 1 & 1 & 1 & 1 & -1 & 1 & -1 & 1 & 1 & -1 & -1 & 1 & 1 & -1 & -1 & 1 & -1 & 1 & -1 & -1 & -1 \\
\hline 3 & -1 & -1 & 1 & 1 & 1 & 1 & 1 & -1 & 1 & -1 & 1 & 1 & -1 & -1 & 1 & 1 & -1 & -1 & 1 & -1 & 1 & -1 & -1 \\
\hline 4 & -1 & -1 & -1 & 1 & 1 & 1 & 1 & 1 & -1 & 1 & -1 & 1 & 1 & -1 & -1 & 1 & 1 & -1 & -1 & 1 & -1 & 1 & -1 \\
\hline 5 & -1 & -1 & -1 & -1 & 1 & 1 & 1 & 1 & 1 & -1 & 1 & -1 & 1 & 1 & -1 & -1 & 1 & 1 & -1 & -1 & 1 & -1 & 1 \\
\hline 6 & 1 & -1 & -1 & -1 & -1 & 1 & 1 & 1 & 1 & 1 & -1 & 1 & -1 & 1 & 1 & -1 & -1 & 1 & 1 & -1 & -1 & 1 & -1 \\
\hline 7 & -1 & 1 & -1 & -1 & -1 & -1 & 1 & 1 & 1 & 1 & 1 & -1 & 1 & -1 & 1 & 1 & -1 & -1 & 1 & 1 & -1 & -1 & 1 \\
\hline 8 & 1 & -1 & 1 & -1 & -1 & -1 & -1 & 1 & 1 & 1 & 1 & 1 & -1 & 1 & -1 & 1 & 1 & -1 & -1 & 1 & 1 & -1 & -1 \\
\hline 9 & -1 & 1 & -1 & 1 & -1 & -1 & -1 & -1 & 1 & 1 & 1 & 1 & 1 & -1 & 1 & -1 & 1 & 1 & -1 & -1 & 1 & 1 & -1 \\
\hline 10 & -1 & -1 & 1 & -1 & 1 & -1 & -1 & -1 & -1 & 1 & 1 & 1 & 1 & 1 & -1 & 1 & -1 & 1 & 1 & -1 & -1 & 1 & 1 \\
\hline 11 & 1 & -1 & -1 & 1 & -1 & 1 & -1 & -1 & -1 & -1 & 1 & 1 & 1 & 1 & 1 & -1 & 1 & -1 & 1 & 1 & -1 & -1 & 1 \\
\hline 12 & 1 & 1 & -1 & -1 & 1 & -1 & 1 & -1 & -1 & -1 & -1 & 1 & 1 & 1 & 1 & 1 & -1 & 1 & -1 & 1 & 1 & -1 & -1 \\
\hline 13 & -1 & 1 & 1 & -1 & -1 & 1 & -1 & 1 & -1 & -1 & -1 & -1 & 1 & 1 & 1 & 1 & 1 & -1 & 1 & -1 & 1 & 1 & -1 \\
\hline 14 & -1 & -1 & 1 & 1 & -1 & -1 & 1 & -1 & 1 & -1 & -1 & -1 & -1 & 1 & 1 & 1 & 1 & 1 & -1 & 1 & -1 & 1 & 1 \\
\hline 15 & 1 & -1 & -1 & 1 & 1 & -1 & -1 & 1 & -1 & 1 & -1 & -1 & -1 & -1 & 1 & 1 & 1 & 1 & 1 & -1 & 1 & -1 & 1 \\
\hline 16 & 1 & 1 & -1 & -1 & 1 & 1 & -1 & -1 & 1 & -1 & 1 & -1 & -1 & -1 & -1 & 1 & 1 & 1 & 1 & 1 & -1 & 1 & -1 \\
\hline 17 & -1 & 1 & 1 & -1 & -1 & 1 & 1 & -1 & -1 & 1 & -1 & 1 & -1 & -1 & -1 & -1 & 1 & 1 & 1 & 1 & 1 & -1 & 1 \\
\hline 18 & 1 & -1 & 1 & 1 & -1 & -1 & 1 & 1 & -1 & -1 & 1 & -1 & 1 & -1 & -1 & -1 & -1 & 1 & 1 & 1 & 1 & 1 & -1 \\
\hline 19 & -1 & 1 & -1 & 1 & 1 & -1 & -1 & 1 & 1 & -1 & -1 & 1 & -1 & 1 & -1 & -1 & -1 & -1 & 1 & 1 & 1 & 1 & 1 \\
\hline 20 & 1 & -1 & 1 & -1 & 1 & 1 & -1 & -1 & 1 & 1 & -1 & -1 & 1 & -1 & 1 & -1 & -1 & -1 & -1 & 1 & 1 & 1 & 1 \\
\hline 21 & 1 & 1 & -1 & 1 & -1 & 1 & 1 & -1 & -1 & 1 & 1 & -1 & -1 & 1 & -1 & 1 & -1 & -1 & -1 & -1 & 1 & 1 & 1 \\
\hline 22 & 1 & 1 & 1 & -1 & 1 & -1 & 1 & 1 & -1 & -1 & 1 & 1 & -1 & -1 & 1 & -1 & 1 & -1 & -1 & -1 & -1 & 1 & 1 \\
\hline 23 & 1 & 1 & 1 & 1 & -1 & 1 & -1 & 1 & 1 & -1 & -1 & 1 & 1 & -1 & -1 & 1 & -1 & 1 & -1 & -1 & -1 & -1 & 1 \\
\hline 24 & -1 & -1 & -1 & -1 & -1 & -1 & -1 & -1 & -1 & -1 & -1 & -1 & -1 & -1 & -1 & -1 & -1 & -1 & -1 & -1 & -1 & -1 & -1 \\
\hline
\end{tabular}


The following first-order model was used to express the response of the PBD:

$$
Y=\beta_{0}+\sum_{i=1}^{22} \beta_{i} X_{i}
$$

where:

$Y=$ Response variable

$\beta_{0}=$ Interception coefficient

$\beta_{i}=$ Coefficients of linear effects of the independent variables $\left(X_{1}-X_{22}\right)$

The effects of the significant variables identified in the PBD was subsequently validated by formulating five different media as shown in Table 11.

Formulation 1 constituted of all the significant variables; Formulation 2 was made up of only the significant variables with positive effect; Formulation 3 was comprised all the variables with stimulatory effects irrespective of their significance level; Formulation 4 contained 4 main components, which represent the carbon source, organic nitrogen source, inorganic nitrogen source and mineral source with the highest positive effect; Formulation 5 constituted of the similar medium composition as Formulation 4 except lactose was replaced with molasses, which exhibited a strong stimulatory effect on the growth and the cost was the lowest among the five carbon sources.

Table 11. Media formulation to validate the effects of significant variables on tryptophan production by P. acidilactici TP-6.

\begin{tabular}{|c|c|}
\hline Media Formulation & Medium Composition, $\mathrm{g} / \mathrm{L}$ \\
\hline \multicolumn{2}{|c|}{ Medium 1} \\
\hline Glucose & 20 \\
\hline Sucrose & 17.69 \\
\hline Lactose & 18.86 \\
\hline Molasses & 25.08 \\
\hline Yeast extract & 4 \\
\hline Peptone & 10 \\
\hline Meat extract & 8 \\
\hline $\mathrm{K}_{2} \mathrm{HPO}_{4}$ & 2 \\
\hline Urea & 3 \\
\hline$\left(\mathrm{NH}_{4}\right)_{2} \mathrm{SO}_{4}$ & 5 \\
\hline$\left(\mathrm{NH}_{4}\right)_{2} \mathrm{HC}_{6} \mathrm{H}_{5} \mathrm{O}_{7}$ & 2 \\
\hline $\mathrm{NaOAc}$ & 5 \\
\hline $\mathrm{MgSO}_{4}$ & 0.2 \\
\hline $\mathrm{MnSO}_{4}$ & 0.04 \\
\hline $\mathrm{FeSO}_{4}$ & 0.01 \\
\hline $\mathrm{CuSO}_{4}$ & 0.01 \\
\hline \multicolumn{2}{|c|}{ Medium 2} \\
\hline Meat extract & 8 \\
\hline $\mathrm{FeSO}_{4}$ & 0.01 \\
\hline Lactose & 18.86 \\
\hline $\mathrm{MnSO}_{4}$ & 0.04 \\
\hline Urea & 3 \\
\hline $\mathrm{CuSO}_{4}$ & 0.01 \\
\hline $\mathrm{K}_{2} \mathrm{HPO}_{4}$ & 2 \\
\hline $\mathrm{MgSO}_{4}$ & 0.2 \\
\hline \multicolumn{2}{|c|}{ Medium 3} \\
\hline Meat extract & 8 \\
\hline $\mathrm{FeSO}_{4}$ & 0.01 \\
\hline Lactose & 18.86 \\
\hline $\mathrm{MnSO}_{4}$ & 0.04 \\
\hline Urea & 3 \\
\hline $\mathrm{CuSO}_{4}$ & 0.01 \\
\hline $\mathrm{K}_{2} \mathrm{HPO}_{4}$ & 2 \\
\hline $\mathrm{MgSO}_{4}$ & 0.2 \\
\hline Biotin & 0.06 \\
\hline Tween 80 & 1 \\
\hline
\end{tabular}


Table 11. Cont.

\begin{tabular}{ccc}
\hline Media Formulation & \multicolumn{2}{c}{ Medium Composition, $\mathrm{g} / \mathrm{L}$} \\
\hline & Medium 4 & 18.86 \\
Lactose & & 8 \\
Meat extract & 3 \\
Urea & & 0.01 \\
$\mathrm{FeSO}_{4}$ & & \\
& Medium 5 & 25.08 \\
Molasses & & 8 \\
Meat extract & 3 \\
Urea & & 0.01 \\
FeSO $_{4}$ & &
\end{tabular}

\subsection{Steepest Ascent Method}

The neighborhood of the optimum concentrations of each significant variable (molasses, meat extract, urea and $\mathrm{FeSO}_{4}$ ) was subsequently estimated by using the steepest ascent method. The direction of ascent or descent of each variable was determined by using the first-order model from PBD as a guideline, where variables bearing a positive sign was moved along the path of Steepest Ascent and vice versa. Meanwhile, the coefficient with the highest value, in this case meat extract was used as a benchmark to compute the step length of urea and $\mathrm{FeSO}_{4}$. Table 12 shows the Steepest Ascent design consisting of 10 steps that governed the production of tryptophan by P. acidilactici TP-6. The concentration of urea and $\mathrm{FeSO}_{4}$ was increased by $20 \%$ and $28.5 \%$ respectively for every $50 \%$ increment of the meat extract concentration. Meanwhile, the molasses concentration was reduced by $10 \%$ at each run.

Table 12. Steepest Ascent design for tryptophan production by P. acidilactici TP-6.

\begin{tabular}{cccccc}
\hline \multirow{2}{*}{ No. } & \multirow{2}{*}{ Run } & \multicolumn{4}{c}{ Variable level, g/L } \\
\cline { 3 - 6 } & & Molasses (A) & Meat Extract (B) & Urea (C) & FeSO $_{\mathbf{4}}$ (D) \\
\hline & $\Delta$ & -2.51 & 4 & 0.6 & 0.003 \\
1 & Origin & 25.08 & 8 & 3.0 & 0.010 \\
2 & Origin $+\Delta$ & 22.57 & 12 & 3.6 & 0.013 \\
3 & Origin $+2 \Delta$ & 20.06 & 16 & 4.2 & 0.016 \\
4 & Origin $+3 \Delta$ & 17.55 & 20 & 4.8 & 0.019 \\
5 & Origin $+4 \Delta$ & 15.04 & 24 & 5.4 & 0.022 \\
6 & Origin $+5 \Delta$ & 12.53 & 28 & 6.0 & 0.025 \\
7 & Origin $+6 \Delta$ & 10.02 & 32 & 6.6 & 0.028 \\
8 & Origin $+7 \Delta$ & 7.51 & 36 & 7.2 & 0.031 \\
9 & Origin $+8 \Delta$ & 5.00 & 40 & 7.8 & 0.034 \\
10 & Origin $+9 \Delta$ & 2.49 & 44 & 8.4 & 0.037 \\
11 & Origin $+10 \Delta$ & 0 & 48 & 9.0 & 0.040 \\
\hline
\end{tabular}

\subsection{Central Composite Design}

Subsequently, the CCD was employed for the determination of optimum concentration of molasses, meat extract, urea and $\mathrm{FeSO}_{4}$ that required for tryptophan production by P. acidilactici TP-6. Design Expert statistical software version 9.0.6.2 (State-Ease Inc, Minneapolis, MN, USA) was used for designing of experiment and statistical analysis. Table 13 presents the details of each medium component used in the CCD, where each variable was assigned to five distinct levels $(-\alpha,-1,0,+1$, $+\alpha)$. The axial distance selected in this study was two, such that the design was rotatable.

Table 14 shows a total of 30 experimental runs suggested by CCD software, comprising of 16 factorial points, 8 axial points and 6 central points. The following second-order model could be used to express the relationship of the response with each variable:

$$
Y=\beta_{0}+\sum \beta_{j} X_{j}+\sum \beta_{j^{2}} X_{j^{2}}+\sum \beta_{j k} X_{j} X_{k}
$$


where:

$Y=$ Response variable

$\beta_{0}=$ Interception coefficient

$\beta_{\mathrm{j}}=$ Linear coefficients

$\beta_{\mathrm{j}}^{2}=$ Quadratic coefficients

$\beta_{\mathrm{jk}}=$ Interactive coefficients

Table 13. Coded and real values of variables selected for CCD of tryptophan production by P. acidilactici TP-6.

\begin{tabular}{ccccccc}
\hline \multirow{2}{*}{ Variables } & $\begin{array}{c}\text { Coded } \\
\text { Symbol }\end{array}$ & \multicolumn{7}{c}{ Coded Values } \\
\cline { 3 - 7 } & & $-\boldsymbol{\alpha}$ & $\mathbf{- 1}$ & $\mathbf{0}$ & $\mathbf{+ 1}$ & $\mathbf{+}$ \\
\hline Molasses & $\mathrm{A}$ & 10.02 & 12.53 & 15.04 & 17.55 & 20.06 \\
Meat extract & $\mathrm{B}$ & 16 & 20 & 24 & 28 & 32 \\
Urea & $\mathrm{C}$ & 4.2 & 4.8 & 5.4 & 6 & 6.6 \\
$\mathrm{FeSO}_{4}$ & $\mathrm{D}$ & 0.016 & 0.019 & 0.022 & 0.025 & 0.028 \\
\hline
\end{tabular}

Table 14. CCD matrix for four variables with coded values for tryptophan production by P. acidilactici TP-6.

\begin{tabular}{|c|c|c|c|c|}
\hline Std Run & $\mathbf{A}$ & B & $\mathrm{C}$ & D \\
\hline 1 & -1 & -1 & -1 & -1 \\
\hline 2 & 1 & -1 & -1 & -1 \\
\hline 3 & -1 & 1 & -1 & -1 \\
\hline 4 & 1 & 1 & -1 & -1 \\
\hline 5 & -1 & -1 & 1 & -1 \\
\hline 6 & 1 & -1 & 1 & -1 \\
\hline 7 & -1 & 1 & 1 & -1 \\
\hline 8 & 1 & 1 & 1 & -1 \\
\hline 9 & -1 & -1 & -1 & 1 \\
\hline 10 & 1 & -1 & -1 & 1 \\
\hline 11 & -1 & 1 & -1 & 1 \\
\hline 12 & 1 & 1 & -1 & 1 \\
\hline 13 & -1 & -1 & 1 & 1 \\
\hline 14 & 1 & -1 & 1 & 1 \\
\hline 15 & -1 & 1 & 1 & 1 \\
\hline 16 & 1 & 1 & 1 & 1 \\
\hline 17 & -2 & 0 & 0 & 0 \\
\hline 18 & 2 & 0 & 0 & 0 \\
\hline 19 & 0 & -2 & 0 & 0 \\
\hline 20 & 0 & 2 & 0 & 0 \\
\hline 21 & 0 & 0 & -2 & 0 \\
\hline 22 & 0 & 0 & 2 & 0 \\
\hline 23 & 0 & 0 & 0 & -2 \\
\hline 24 & 0 & 0 & 0 & 2 \\
\hline 25 & 0 & 0 & 0 & 0 \\
\hline 26 & 0 & 0 & 0 & 0 \\
\hline 27 & 0 & 0 & 0 & 0 \\
\hline 28 & 0 & 0 & 0 & 0 \\
\hline 29 & 0 & 0 & 0 & 0 \\
\hline 30 & 0 & 0 & 0 & 0 \\
\hline
\end{tabular}

\subsection{Production of Tryptophan}

Cultivation of the bacterial strain for tryptophan production was performed by inoculating $10 \%$ $(v / v)$ of inoculum into the media, followed by incubation for $20 \mathrm{~h}$ at $30^{\circ} \mathrm{C}$ [25]. 


\subsection{Analytical Methods}

The tryptophan content of the cultured broth was determined after separation of biomass by centrifugation for $10 \mathrm{~min}$ at $10,000 \times g, 4^{\circ} \mathrm{C}$. Meanwhile, the cell growth was determined by using the biomass. The determination of cell population and tryptophan content was conducted as described by Lim et al. [60].

\section{Conclusions}

Seventeen of the 22 studied variables were found to exhibit significant effects $(p<0.05)$ on the production of tryptophan by $P$. acidilactici TP-6, while the remaining 5 variables including fructose, $\mathrm{KH}_{2} \mathrm{PO}_{4}$, Tween $80, \mathrm{ZnSO}_{4}$ and biotin did not affect the net tryptophan produced significantly $(p>0.05)$. On the other hand, s16 variables contributed significantly $(p<0.05)$ to the growth of P. acidilactici TP-6, except for fructose, lactose, $\mathrm{KH}_{2} \mathrm{PO}_{4}$, urea, $\mathrm{NH}_{4} \mathrm{NO}_{3}$ and $\mathrm{FeSO}_{4}$, which had no significant effect $(p>0.05)$ on the cell growth of P. acidilactici TP-6. A medium constituting of molasses, meat extract, urea and $\mathrm{FeSO}_{4}$ was proven to be the best medium for the production of tryptophan by P. acidilactici TP-6, where it permitted the highest amount of tryptophan production $(25.95 \mathrm{mg} / \mathrm{L})$ with the additional advantage of cost competitiveness. Furthermore, the tryptophan production was comparable to the control MRS medium with no significant difference $(p>0.05)$. Hence, molasses, meat extract, urea and $\mathrm{FeSO}_{4}$ were subsequently selected for further optimization. The application of the Steepest Ascent procedure has successfully improved the net tryptophan produced by approximately 2.5 folds, from $27 \mathrm{mg} / \mathrm{L}$ at run 1 to $69.05 \mathrm{mg} / \mathrm{L}$ at run 5 . Subsequently, the optimum concentration of each medium components was determined by using CCD and it was suggested that the highest predicted tryptophan production $(70.38 \mathrm{mg} / \mathrm{L})$ could be achieved by using the combination of molasses $(14.06 \mathrm{~g} / \mathrm{L})$, meat extract $(23.68 \mathrm{~g} / \mathrm{L})$, urea $(5.56 \mathrm{~g} / \mathrm{L})$ and $\mathrm{FeSO}_{4}(0.024 \mathrm{~g} / \mathrm{L})$. An amount of $68.05 \mathrm{mg} / \mathrm{L}$ of tryptophan was produced by P. acidilactici TP-6 upon validation by cultivating the producer strain in the optimized medium. There was no significant difference $(p>0.05)$ between the tryptophan production predicted by the model with the experimental tryptophan production. Up to $150 \%$ enhancement of tryptophan production by P. acidilactici TP- 6 was achieved by using the optimized medium, whereas the cost of the fermentation medium was reduced by $11 \%$ as compared to the control MRS medium.

Author Contributions: Conceptualization, H.L.F. and T.C.L.; Data curation, R.M. and H.L.F.; Formal analysis, Y.H.L. and H.L.F.; Funding acquisition, H.L.F., T.C.L. and R.A.R.; Investigation, Y.H.L. and H.L.F.; Methodology, Y.H.L., R.M. and H.L.F.; Project administration, H.L.F. and T.C.L.; Resources, H.L.F. and T.C.L.; Supervision, H.L.F. and R.M.; Validation, H.L.F., R.M. and R.A.R.; Writing-original draft, Y.H.L. and H.L.F.; Writing-review \& editing, Y.H.L., H.L.F. and T.C.L. All authors have read and agreed to the published version of the manuscript.

Funding: This research was funded by Ministry of Education Malaysia, grant number UPM/700-1/3/LRGS.

Acknowledgments: The authors would like to thank Ministry of Education of Malaysia for funding the research grant under Long-Term Research Grant Scheme (LRGS).

Conflicts of Interest: The authors declare no conflict of interest.

\begin{tabular}{|c|c|}
\hline \multicolumn{2}{|c|}{ Abbreviations } \\
\hline LAB & Lactic acid bacteria \\
\hline RSM & Response surface methodology \\
\hline PBD & Plackett-Burman Design \\
\hline CCD & Central Composite Design \\
\hline PLP & Pyridoxal phosphate \\
\hline MRS & deMan, Rogosa and Sharpe \\
\hline SEM & Standard error of mean \\
\hline HPLC & High performance liquid chromatography \\
\hline OPA & o-phthalaldehyde \\
\hline FMOC & 9-fluorenylmethyl chloroformate \\
\hline
\end{tabular}




\section{References}

1. Panda, B.P.; Ali, M.; Javed, S. Fermentation process optimization. Res. J. Microbiol. 2007, 2, 201-208.

2. Weuster-Botz, D. Experimental design for fermentation media development: Statistical design or global random search. J. Biosci. Bioeng. 2000, 90, 473-483. [CrossRef]

3. Elibol, M. Optimization of medium composition for actinorhodin production by Streptomyces coelicolor A3 with response surface methodology. Process. Biochem. 2004, 39, 1057-1062. [CrossRef]

4. Djekrif-Dakhmouche, S.; Gheribi-Aoulmi, Z.; Meraihi, Z.; Bennamoun, L. Application of a statistical design to the optimization of culture medium for $\alpha$-amylase production by Aspergillus niger ATCC 16404 grown on orange waste powder. J. Food. Eng. 2006, 73, 190-197. [CrossRef]

5. Chen, H.; Xu, X.Q.; Zhu, Y. Optimization of hydroxyl radical scavenging activity of exo-polysaccharides from Inonotus obliquus in submerged fermentation using response surface methodology. J. Microbiol. Biotechnol. 2010, 20, 835-843.

6. Vohra, A.; Satyanarayana, T. Statistical optimization of the medium components by response surface methodology to enhance phytase production by Pichia anomala. Process. Biochem. 2002, 37, 999-1004. [CrossRef]

7. Montserrat, S.; Iñaki, R.; François, O.; Francesc, G.; Carles, C. Application of factorial design to the optimization of medium composition in batch cultures of Streptomyces lividans TK21 producing a hybrid antibiotic. Biotechnol. Lett. 1993, 15, 559-564. [CrossRef]

8. Faghfuri, E.; Fooladi, J.; Moosavi-Nejad, S.Z. L-tryptophan production by whole cells of Escherichia coli based on Iranian sugar beet molasses. Jundishapur J. Microbiol. 2013, 6, 1-5. [CrossRef]

9. Cheng, L.K.; Wang, J.; Xu, Q.Y.; Xie, X.X.; Zhang, Y.J.; Zhao, C.G.; Chen, N. Effect of feeding strategy on L-tryptophan production by recombinant Escherichia coli. Ann. Microbiol. 2012, 62, 1625-1634. [CrossRef]

10. Hagino, H.; Nakayama, K. L-tryptophan production by analog-resistant mutants derived from a phenylalanine and tyrosine double auxotroph of Corynebacterium glutamicum. Agric. Biol. Chem. 1975, 39, 343-349.

11. Toe, C.J.; Foo, H.L.; Loh, T.C.; Rosfarizan, M.; Raha, A.R.; Zulkifli, I. Extracellular proteolytic activity and amino acid production by lactic acid bacteria Isolated from Malaysian foods. Int. J. Mol. Sci. 2019, 20, 1777. [CrossRef] [PubMed]

12. Norfarina, M.N.; Mohd Shamzi, M.; Loh, T.C.; Foo, H.L.; Raha, A.R.; Tan, J.S.; Rosfarizan, M. Comparative analyses on medium optimization using one-factor-at-a-time, response surface methodology and artificial neural network for lysine-methionine biosynthesis by Pediococcus pentosaceus RF-1. Biotechnol. Biotechnol. Equip. 2017, 31, 935-947.

13. Izuddin, W.I.; Loh, T.C.; Foo, H.L.; Samsudin, A.A.; Humam, A.M. Postbiotic, L. Plantarum RG14 improves ruminal epithelium growth, immune status and upregulates the intestinal barrier function in post-weaning lambs. Sci. Rep. 2019, 9, 9938. [CrossRef] [PubMed]

14. Abdulla, N.R.; Mohd Zamri, A.N.; Sabow, A.B.; Kareem, K.Y.; Nurhazirah, S.; Foo, H.L.; Awis, Q.S.; Loh, T.C. Physico-Chemical properties of breast muscle in broiler chickens fed probiotics, antibiotics or antibiotic-probiotic mix. J. Appl. Anim. Res. 2017, 45, 64-70. [CrossRef]

15. Kareem, K.Y.; Loh, T.C.; Foo, H.L.; Asmara, S.A.; Akit, H. Influence of postbiotic RG14 and inulin combination on cecal microbiota, organic acid concentration and cytokine expression in broiler chickens. Poult. Sci. 2016, 96, 966-975. [CrossRef]

16. Kareem, K.Y.; Loh, T.C.; Foo, H.L.; Asmara, S.A.; Akit, H.; Abdulla, N.R.; Ooi, M.F. Carcass, meat and bone quality of broiler chickens fed with postbiotic and prebiotic combinations. Int. J. Probiotzics Prebiotics 2015, $10,23$.

17. Leuchtenberger, W.; Huthmacher, K.; Drauz, K. Biotechnological production of amino acids and derivatives: Current status and prospects. Appl. Microbiol. Biot. 2005, 69, 1-8. [CrossRef]

18. Rosebrough, R.W. Crude protein and supplemental dietary tryptophan effects on growth and tissue neurotransmitter levels in the broiler chicken. Br. J. Nutr. 1996, 76, 87-96. [CrossRef]

19. Moshirfar, A.; Kamara, K.; Castonguay, T.W. Intragastrically administered tryptophan blocks gluconeogenesis in 48-hr starved rats. J. Nutr. Biochem. 1996, 7, 567-570. [CrossRef]

20. Iwuji, T.C.; Akinmutimi, A.H.; Ogbuewu, I.P.; Etuk, I.F.; Odoemelam, V.U. Roles of tryptophan in monogastric nutrition: A review. Adv. Agric. Sci. Eng. Res. 2014, 4, 1544-1556. 
21. Duarte, K.F.; Junqueira, O.M.; Filardi, R.D.S.; Siqueira, J.C.D.; Puzotti, M.M.; Garcia, E.A.; Molino, A.D.B.; Laurentiz, A.C.D. Digestible tryptophan requirements for broilers from 22 to 42 days old. R. Bras. Zootec. 2013, 42, 728-733. [CrossRef]

22. Mateus, D.M.R.; Alves, S.S.; Da Fonseca, M.M.R. Kinetics of L-tryptophan production from indole and L-serine catalyzed by whole cells with tryptophanase activity. J. Biosci. Bioeng. 2004, 97, 289-293. [CrossRef]

23. Turner, E.H.; Loftis, J.M.; Blackwell, A.D. Serotonin a la carte: Supplementation with the serotonin precursor 5-hydroxytryptophan. Pharmacol. Ther. 2006, 109, 325-338. [CrossRef] [PubMed]

24. Tarek, M.; Hesham, H.M. Screening of potential infants' Lactobacilli isolates for amino acids production. Afr. J. Microbiol. Res. 2010, 4, 226-232.

25. Lim, Y.H.; Foo, H.L.; Loh, T.C.; Rosfarizan, M.; Norhani, A. Comparative studies of versatile extracellular proteolytic activities of lactic acid bacteria and their potential for extracellular amino acid productions as feed supplements. J. Anim. Sci. Biotechnol. 2019, 10, 1-13. [CrossRef]

26. Miller, J.N. Experimental design and optimisation (4): Plackett-Burman designs. Anal. Methods 2013, 5, 1901-1903.

27. Li, Y.; Liu, Z.; Zhao, H.; Xu, Y.; Cui, F. Statistical optimization of xylanase production from new isolated Penicillium oxalicum ZH-30 in submerged fermentation. Biochem. Eng. J. 2007, 34, 82-86. [CrossRef]

28. Pirie, P.; Naeimpoor, F.; Hejazi, P. A microcosm study on P-Nitrophenol biodegradation in soil slurry by Alcaligenes faecalis: Plackett-Burman design. Iran. J. Chem. Eng. 2011, 8, 57-68.

29. Voet, D.; Voet, J.G. Biochemistry, 3rd ed.; John Wiley and Sons, Inc.: Hoboken, NJ, USA, 2004.

30. Tavakkoli, M.; Hamidi-Esfahani, Z.; Azizi, M.H. Optimization of Corynebacterium glutamicum glutamic acid production by response surface methodology. Food Bioproc. Tech. 2012, 5, 92-99. [CrossRef]

31. Li, J.; Ma, C.; Ma, Y.; Li, Y.; Zhou, W.; Xu, P. Medium optimization by combination of response surface methodology and desirability function: An application in glutamine production. Appl. Microbiol. Biotechnol. 2007, 74, 563-571. [CrossRef] [PubMed]

32. Kiefer, P.; Heinzle, E.; Wittmann, C. Influence of glucose, fructose and sucrose as carbon sources on kinetics and stoichiometry of lysine production by Corynebacterium glutamicum. J. Ind. Microbiol. Biotechnol. 2002, 28, 338-343. [CrossRef] [PubMed]

33. Lee, M.H.; Lee, H.W.; Park, J.H.; Ahn, J.O.; Jung, J.K.; Hwang, Y.I. Improved L-threonine production of Escherichia coli mutant by optimization of culture conditions. J. Biosci. Bioeng. 2006, 101, 127-130. [CrossRef] [PubMed]

34. Okamoto, K.; Ikeda, M. Development of an industrially stable process for L-threonine fermentation by an L-methionine-auxotrophic mutant of Escherichia coli. J. Biosci. Bioeng. 2000, 89, 87-89. [CrossRef]

35. Chen, N.; Huang, J.; Feng, Z.B.; Yu, L.; Xu, Q.Y.; Wen, T.Y. Optimization of fermentation conditions for the biosynthesis of L-threonine by Escherichia coli. Appl. Biochem. Biotechnol. 2009, 158, 595-604. [CrossRef]

36. Wang, J.; Cheng, L.K.; Chen, N. High-level production of L-threonine by recombinant Escherichia coli with combined feeding strategies. Biotechnol. Biotechnol. Equip. 2014, 28, 495-501. [CrossRef]

37. Roy, D.K.; Chatterjee, S.P. Production of glutamic acid by Arthrobacter globiformis: Influence of cultural conditions. Folia Microbiol. 1989, 34, 11-24. [CrossRef]

38. Coruzzi, G.; Last, R.; Dudareva, N.; Amrhein, N. Amino Acids. In Biochemistry and Molecular Biology of Plants; Buchanan, B.B., Gruissem, W., Jones, R.L., Eds.; John Wiley and Sons, Inc.: Hoboken, NJ, USA, 2015; pp. 289-336.

39. Alexander, J.C.; Beckneh, C.; Elvehjem, C.A. The alanine, cystine, glycine and serine content of meat. J. Nutr. 1953, 51, 319-328. [CrossRef]

40. Powers, H.J. Riboflavin (vitamin B-2) and health. Am. J. Clin. Nutr. 2003, 77, 1352-1360. [CrossRef]

41. Osborne, A.; Thorneley, R.N.; Abell, C.; Bornemann, S. Studies with substrate and cofactor analogues provide evidence for a radical mechanism in the chorismate synthase reaction. J. Biol. Chem. 2000, 275, 35825-35830. [CrossRef]

42. Lin, X.; Xu, S.; Yang, Y.; Wu, J.; Wang, H.; Shen, H.; Wang, H. Purification and characterization of anthranilate synthase component I (TrpE) from Mycobacterium tuberculosis H37Rv. Protein Expr. Purif. 2009, 64, 8-15. [CrossRef]

43. Davati, N.; Hamidi Esfahani, Z.; Shojaosadati, S.A. Optimization of medium composition for microbial production of glutamic acid from Date fruit wastes using fractional factorial method. Iran. J. Food Sci. Technol. 2010, 7, 61-67. 
44. Nampoothiri, K.M.; Pandey, A. Solid state fermentation for L-glutamic acid production using Brevibacterium sp. Biotechnol. Lett. 1996, 18, 199-204. [CrossRef]

45. Zareian, M.; Ebrahimpour, A.; Bakar, F.A.; Mohamed, A.K.S.; Forghani, B.; Ab-Kadir, M.S.B.; Saari, N. A glutamic acid-producing lactic acid bacteria isolated from Malaysian fermented foods. Int. J. Mol. Sci. 2012, 13, 5482-5497. [CrossRef]

46. Ikeda, M.; Katsumata, R. Metabolic engineering to produce tyrosine or phenylalanine in a tryptophan-producing Corynebacterium glutamicum strain. Appl. Environ. Microbiol. 1992, 58, 781-785. [CrossRef]

47. Rodwell, V.; Bender, D.; Botham, K.M.; Kennelly, P.J.; Weil, P.A. Harper's Illustrated Biochemistry, 30th ed.; McGraw-Hill Education: New York, NY, USA, 2015.

48. Zalkin, H.; Kling, D. Anthranilate synthetase. Purification and properties of component I from Salmonella typhimurium. Biochemistry 1968, 7, 3566-3573. [CrossRef] [PubMed]

49. Hertel, S.C.; Hieke, M.; Gröger, D. Anthranilate synthase from Ruta graveolens: Partial purification and properties. Biochem. Physiol. Pflanz. 1991, 187, 121-129. [CrossRef]

50. Widholm, J. Anthranilate synthetase from 5-methyltryptophan-susceptible and-resistant cultured Daucus carota cells. Biochim. Biophys. Acta. 1972, 279, 48-57. [CrossRef]

51. Momose, H.; Takagi, T. Glutamic acid production in biotin-rich media by temperature-sensitive mutants of Brevibacterium lactofermentum, a novel fermentation process. Agric. Biol. Chem. 1978, 42, 1911-1917. [CrossRef]

52. Todorov, S.D.; Dicks, L.M. Bacteriocin production by Lactobacillus pentosus ST712BZ isolated from boza. Braz. J. Microbiol. 2007, 38, 166-172. [CrossRef]

53. Saraniya, A.; Jeevaratnam, K. Optimization of nutritional and non-nutritional factors involved for production of antimicrobial compounds from Lactobacillus pentosus SJ65 using response surface methodology. Braz. J. Microbiol. 2014, 45, 81-88. [CrossRef] [PubMed]

54. Saeed, A.H.; Salam, A.I. Current limitations and challenges with lactic acid bacteria: A review. Food Nutr. Sci. 2013, 4, 73-87.

55. de Carvalho, A.A.T.; Mantovani, H.C.; Paiva, A.D.; De Melo, M.R. The effect of carbon and nitrogen sources on bovicin HC5 production by Streptococcus bovis HC5. J. Appl. Microbiol. 2009, 107, 339-347. [CrossRef] [PubMed]

56. Oh, H.; Wee, Y.J.; Yun, J.S.; Han, S.H.; Jung, S.; Ryu, H.W. Lactic acid production from agricultural resources as cheap raw materials. Bioresour. Technol. 2005, 96, 1492-1498. [CrossRef] [PubMed]

57. Mohamed, I.A.; Loh, T.C.; Foo, H.L.; Lau, W.H.; Awis, Q.S. Biodegradation of palm kernel cake by cellulolytic and hemicellulolytic bacterial cultures through solid state fermentation. Sci. World J. 2014, 2014, 1-8. [CrossRef] [PubMed]

58. Rodrigues, L.; Teixeira, J.; Oliveira, R.; Van Der Mei, H.C. Response surface optimization of the medium components for the production of biosurfactants by probiotic bacteria. Process. Biochem. 2006, 41, 1-10. [CrossRef]

59. Ooi, M.F.; Nurzafirah, M.; Foo, H.L.; Loh, T.C.; Rosfarizan, M.; Raha, A.R.; Arbakariya, A. Effects of carbon and nitrogen sources on bacteriocin-inhibitory activity of postbiotic metabolites produced by Lactobacillus plantarum I-UL4. Malays. J. Microbiol. 2015, 11, 176-184.

60. Lim, Y.H.; Foo, H.L.; Loh, T.C.; Rosfarizan, M.; Raha, A.R.; Zulkifli, I. Optimized medium via statistical approach enhanced threonine production by Pediococcus pentosaceus TL-3 isolated from Malaysian food. Microb. Cell Fact. 2019, 18, 1-19. [CrossRef]

61. Hwang, C.F.; Chang, J.H.; Houng, J.Y.; Tsai, C.C.; Lin, C.K.; Tsen, H.Y. Optimization of medium composition for improving biomass production of Lactobacillus plantarum Pi06 using the Taguchi array design and the Box-Behnken method. Biotechnol. Bioprocess. Eng. 2012, 17, 827-834. [CrossRef]

62. Hutkins, R.W. Microbiology and Technology of Fermented Foods; Blackwell Publishing: Ames, IA, USA, 2008; Volume 22.

63. de Carvalho, I.P.C.; Detmann, E.; Mantovani, H.C.; Paulino, M.F.; Valadares Filho, S.D.C.; Costa, V.A.C.; Gomes, D.I. Growth and antimicrobial activity of lactic acid bacteria from rumen fluid according to energy or nitrogen source. Rev. Bras. Zootec. 2011, 40, 1260-1265. [CrossRef]

64. Thu, T.V.; Foo, H.L.; Loh, T.C.; Bejo, M.H. Inhibitory activity and organic acid concentrations of metabolite combinations produced by various strains of Lactobacillus plantarum. Afr. J. Biotechnol. 2011, 10, 1359-1363. 
65. Tomas, J.M.S.; Bru, E.; Nader-Macia, M.E. Different combinations of salts affect the growth and bacteriocin production by Lactobacillus salivarius CRL 1328. J. Chem. Technol. Biotechnol. 2010, 85, 91-99. [CrossRef]

66. Foucaud, C.; Francois, A.; Richard, J. Development of a chemically defined medium for the growth of Leuconostoc mesenteroides. Appl. Environ. Microbiol. 1997, 63, 301-304. [CrossRef] [PubMed]

67. Li, J.Y.; Zhang, L.W.; Du, M.; Han, X.; Yi, H.X.; Guo, C.F.; Zhang, Y.C.; Luo, X.; Zhang, Y.H.; Shan, Y.J.; et al. Effect of tween series on growth and cis-9, trans-11 conjugated linoleic acid production of Lactobacillus acidophilus F0221 in the presence of bile salts. Int. J. Mol. Sci. 2011, 12, 9138-9154. [CrossRef]

68. Oh, S.; Rheem, S.; Sim, J.; Kim, S.; Baek, Y. Optimizing conditions for the growth of Lactobacillus casei YIT 9018 in tryptone-yeast extract-glucose medium by using response surface methodology. Appl. Environ. Microbiol. 1995, 61, 3809-3814. [CrossRef] [PubMed]

69. Tripuraneni, S. Effect of Nutrient Supplements on Cucumber Fermentation by Lactic Acid Bacteria. Master's Thesis, University of Arkansas, Little Rock, AR, USA, 2011.

70. Rosen, K. Production of Baker's Yeast. In Yeast Biotechnology; Berry, D.R., Russell, I., Steward, G.C., Eds.; Unwin Hyman Ltd.: London, UK, 2012; pp. 471-500.

71. Simova, E.; Simov, Z.; Beshkova, D.; Frengova, G.; Dimitrov, Z.; Spasov, Z. Amino acid profiles of lactic acid bacteria, isolated from kefir grains and kefir starter made from them. Int. J. Food. Microbiol. 2006, 107, 112-123. [CrossRef]

72. Lim, Y.S. Isolation of Bacteriocinogenic Lactic Acid Bacteria and Purification of Selected Bacteriocins from Traditional Fermented Foods. Master's Thesis, Universiti Putra Malaysia, Serdang, Malaysia, 2003.

73. Kareem, K.Y.; Foo, H.L.; Loh, T.C.; Ooi, M.F.; Asmara, S.A. Inhibitory activity of postbiotic produced by strains of Lactobacillus plantarum using reconstituted media supplemented with inulin. Gut. Pathog. 2014, 6, 1-7. [CrossRef]

74. Azin, A.; Rosfarizan, M.; Raha, A.R.; Rosli, M.I.; Farideh, N.; Tan, J.S.; Sahar, A. Cyclodextrin glycosyltransferase biosynthesis improvement by recombinant Lactococcus lactis NZ: NSP: CGT: Medium formulation and culture condition optimization. Biotechnol. Biotechnol. Equip. 2015, 29, 555-563.

Sample Availability: Samples of the compounds are not available from the authors.

(C) 2020 by the authors. Licensee MDPI, Basel, Switzerland. This article is an open access article distributed under the terms and conditions of the Creative Commons Attribution (CC BY) license (http://creativecommons.org/licenses/by/4.0/). 